\title{
Chapter
} 6

\section{Pensando-fazendo Sistemas de Informação com Ética. Da pesquisa à engenharia, e vice-versa.}

\author{
Luiz Paulo Carvalho, Flávia Maria Santoro, Rosa Maria M. Costa, Jonice \\ Oliveira
}

\begin{abstract}
Our goal is to address concepts and definitions of Ethics and how they apply to Information Systems, both from a practical and research point of view. For this, the topics of ethics applied to research in Information Systems and ethics applied to Information Systems engineering will be conducted. Real cases and current and future perspectives and interaction are presented and discussed. We cover the relationship between Ethics and Information Systems, including recurring and essential topics in both thinking and making information systems, data protection and privacy, cyber crimes, intellectual property, professional ethics, plagiarism, consent, ethics committee, among others.
\end{abstract}

\section{Resumo}

Nosso objetivo consiste em abordar conceitos e definições de Ética e como se aplicam à Sistemas de Informação, tanto do ponto de vista prático como da pesquisa. Para isso, serão conduzidos os temas de ética aplicada à pesquisa em Sistemas de Informação e ética aplicada à engenharia de Sistemas de Informação. São apresentados e discutidos casos reais e perspectivas atuais e futuras e interação. Cobrimos a relação entre a Ética e Sistemas de Informação, incluindo tópicos recorrentes e essenciais tanto ao pensar quanto ao fazer sistemas de informação, proteção de dados e privacidade, crimes cibernéticos, propriedade intelectual, ética profissional, plágio, consentimento, comitê de ética, entre outros.

\subsection{Introdução}

Ética é um tema oriundo da Filosofia pouco abordado nos melhores cursos de Computação brasileiros, como oficialmente categorizados e classificados no Brasil pelo Ministério da 
Educação e Cultura (MEC) [Carvalho et al. 2021a]. Como a área que analisa as práticas humanas, assim como suas consequências, podemos fazer diversos atravessamentos associativos à prática da engenharia de soluções computacionais e à prática da pesquisa em Computação. A ausência de consciência ou base Ética na formação da proficiência em Computação, seja formal [Carvalho et al. 2021a] ou informal [Carvalho et al. 2021b], aliena os praticantes da Computação sobre o pensa-fazer associado aos valores, diretos ou indiretos, de suas ações.

Neste trabalho buscamos fugir de uma limitação estruturalista e seguimos duas linhas, o pensar em Computação, tradicionalmente nomeada "estudo" e o fazer Computação, tradicionalmente nomeada "design" ou "construção". Neste sentido, consideramos a opção pensar-fazer (ou fazer-pensar), combinando as percepções de ambas as práticas. Cabe uma ressalva, que também será reforçada nas Seções 6.3 e 6.4, ao tratarmos de pesquisar e engenheirar ${ }^{1}$ há tanto formalização quanto adequação às instituições sociais associadas a estas práticas. Para que um estudo seja considerado uma pesquisa, e um design ou construção seja considerado uma engenharia há necessidade de metodologias e métodos bem-estruturados e estabelecidos às suas epistemologias, conceituais ou práticas. Estão alicerçadas sobre certo rigor paradigmático, metodológico e metódico. Isto não desqualifica ou diminui a qualidade de estudos, designs ou construções informais, cada um tem a sua pertinência e importância.

Há uma diferença entre Sistemas de Informação (SI) enquanto área ou disciplina de conhecimento, e sistema de informação enquanto um tipo de sistema envolvendo dados e informações. O primeiro tem propriedade de elemento único, como ramo científico; o segundo é uma instância de categoria estruturada e delimitada de sistema, i.e., há diversos sistemas de informação enquanto soluções computacionais enquanto Sistemas de Informação assume caráter de área científica.

Sistemas de Informação (SI) é uma área Sociotécnica que abarca, estruturalmente, três aspectos centrados em soluções computacionais, ou um ecossistema destas: comportamental ou humano; organizacional ou procedimental; técnico ou tecnológico. Diferente de Ciência da Computação (CC), que podemos dizer ser a irmã mais velha de SI, ela não necessita imprescindivelmente de elementos computacionais [Stair e Reynolds 2018]. Por exemplo, um comerciante, em uma feira de rua, que registra suas operações e transações comerciais em um caderno enquadra-se em SI, isto é, o aspecto técnico é o caderno, a caneta utilizada para escrever, o marcador de página, e suas especificidades técnicas. Partindo desde exemplo, há determinado consenso na literatura indicando que a adoção de soluções computacionais auxilia as operações e transações deste feirante [Stair e Reynolds 2018, Laudon e Laudon 2020]. Perceba que "adotar solução computacional" é uma prática, dotada de valores, e cabível de ponderação ética. Indicar que a adoção de solução computacional é "um avanço" ou "melhora" independente de contexto, i.e., variáveis espaciais e temporais; extrapola a essência ética, melhor adequada à uma normatividade tecno-determinística. Após uma ponderação ética desligada de pré-concepções, manter o uso do caderno ou optar por outra abordagem não-computacional são opções

\footnotetext{
${ }^{1} \mathrm{O}$ dicionário Caldas Aulete define o verbo engenheirar como "Exercer a profissão de engenheiro, exercer atividade relacionada a engenharia". Disponível em: https://www.aulete.com.br/engenheirar. Disponível em: 01/09/2021
} 
válidas e alinhadas com SI. Encaminhamentos análogos seriam, "por que ter um perfil em Rede Social Online (RSO)?", "por que ter uma Alexa?", "por que compartilhar determinada publicação em uma RSO?", "por que programar em Python?", ou "por que baixar um jogo pirata?", direta ou indiretamente todos estas são reflexões éticas.

A análise pautada em SI precisa transcender, ou transbordar, o aspecto técnico. E apesar de cada um dos três aspectos ter mais ou menos importância dependendo da análise, busca-se uma compensação e parcimônia entre estes. O pensamento predominante e reducionista empurra o "fracasso" de uma solução computacional aos aspectos não-técnicos, i.e., os dois outros aspectos são os responsáveis pela "derrota" do sistema "perfeito", supostamente a cultura, a educação, hábitos, costumes, leis, normas, processos, mentalidade, dentre outros. Analisando pelo viés de SI, a complexidade engloba também o técnico e busca uma visão ampla, e mesmo que, de fato, o ônus recai majoritariamente sobre os aspectos procedimentais ou comportamentais, o aspecto técnico não é "isento" ou livre de valores neste jogo de forças. Concluindo, enquanto a visão tecnicista positivista determinística empurra toda a valoração negativa aos aspectos não-técnicos, SI abraça uma ponderação plural e se afasta de, por exemplo, "é esse povo burro e maleducado, essas leis ruins e esses processos mal estruturados que levaram nosso sistema incrível e perfeito ao fracasso". Neste exemplo, pensando em SI, os elementos responsáveis pelo pensar-fazer deste sistema que falharam, ao desconsiderar ou menosprezar as especificidades de fato e de valor do aspecto comportamental (instrução e educação) e procedimental (leis e processos).

[Stair e Reynolds 2018] definem sistemas de informação como: "Conjunto de componentes inter-relacionados que coletam, processam, armazenam e disseminam dados e informações; um sistema de informações provê mecanismos para monitorar e controlar suas operações, garantindo que continue a cumprir seus fins e alcançar seus objetivos" 2 [tradução nossa]. Por exemplo, um automóvel com soluções computacionais embarcadas, instaladas ou embutidas; que ajudam o motorista a analisar o estado do próprio veículo, estacionar, acompanhar a previsão do tempo, interagir com mapas, evitar tráfego intenso, elaborar rotas e, em grau próximo ao máximo de automatização, dirigir. O pensar-fazer de todas estas funcionalidades é passível de ponderação ética, assim como suas aplicações, seus impactos e suas influências. Com este exemplo podemos ilustrar a diferença central nas imanências de CC e SI, enquanto CC pensa estas funcionalidades como fim em si, SI pensa este sistema enquanto aplicação, impacto e influência. Por exemplo, CC pensa em processamento gráfico para melhorar as interações com e representações de mapas; SI pensa sobre formas de comunicar estas informações gráficas acessíveis a determinado público-alvo, sobre as áreas marginalizadas ou periféricas ignoradas pelos mapeamentos automatizados ou exposição de dados relevantes para determinada necessidade.

Alguns outros sistemas de informação estão comumente presentes no nosso diaa-dia, mesmo que o exemplo do automóvel recheie nossa imaginação com idealismo tecnológico fantasioso. Por exemplo, caixas de supermercado, farmácias, padarias, dentre outros utilizam uma categoria de sistema de informação chamada Sistema de Processa-

\footnotetext{
2 "A set of interrelated components that collect, process, store, and disseminate data and information; an information system provides a feedback mechanism to monitor and control its operation to make sure it continues to meet its goals and objectives." [Stair e Reynolds 2018]
} 
mento de Transação (SPT). Até 2020 este era o exemplo mais simples e vinculado com nossa rotina diária, com a pandemia de COVID-19, e seus efeitos colaterais, a migração ao digital intensificou-se e o SPT mais usual, para muitos, se tornou sistemas de comércio eletrônico (e-commerce), e.g., Mercado Livre, Shopee, Amazon, Magazine Luiza, OLX, dentre outros.

Aspectos técnicos em SI não estão restritos ao software, compreendem também hardware, armazenamento de dados e redes [Stair e Reynolds 2018]. Por exemplo, um sistema de reconhecimento facial: (i) o software é, intuitivamente, o algoritmo de Inteligência Artificial (IA) que processa as imagens, os demais códigos envolvidos; (ii) hardware, as câmeras que capturam as faces; (iii) armazenamento de dados, tanto os dados armazenados após coleta pelas câmeras, quanto os dados presentes na base de dados dedicada à operação da IA; (iv) redes, os meios de transmissão de dados, consideremos uma estruturada cabeada neste cenário. Apenas este aspecto, cabe lembrar, não contempla o contexto de análise em SI, ainda faltam os aspectos procedimental e comportamental.

Neste sentido, precisamos nos afastar do padrão tradicionalista de sistemas de informação e pensar em SI para analisar casos por vias menos positivísticas ou determinísticas, como o fenômeno de compras online durante a pandemia de COVID-19. Pelo aspecto técnico isolado, implementar um sistema de informação e-commerce é a opção com melhores resultados e indicadores. Com este sistema todo o processo é automatizado, os clientes são cadastrados, o pagamento é efetivado com maior segurança, todas as transações são registradas, há possibilidade de controle de estoque, o cliente escolhe os produtos com mais precisão, e os dados estruturados neste $e$-commerce podem alimentar iniciativas de Inteligência do Negócio, servindo de insumo para melhorias do próprio sistema e no negócio [Stair e Reynolds 2018, Laudon e Laudon 2020]. Entretanto, diferente deste apogeu tecno-centrado, negócios se adaptaram de outras formas ${ }^{3}$ :

\begin{abstract}
"Os empresários do setor de supermercados que não podem ou não querem investir nas vendas on-line porque sabem que elas não vão atingir seu público, tem usado de um recurso simples para oferecer um atendimento diferenciado, que são os pedidos pelo aplicativo de mensagens whatsapp. Muitos estabelecimentos passaram a oferecer o serviço no início da pandemia, pois sentiram que essa era uma necessidade para várias famílias e principalmente para os idosos que por medo de serem contaminados evitavam ao máximo sair de casa. [...] Sobre a possibilidade de migrar para as venda on-line nas plataformas especializadas, Adriane acredita que ainda não é o momento, pois teria que mexer muito na estrutura da loja. 'Nem para aplicativos de delivery de comida como o ifood. A maneira como está hoje é a ideal, nossa logística própria é mais barata e o cliente está satisfeito com o serviço', argumenta."
\end{abstract}

Um sistema tradicionalmente utilizado para conversação foi expropriado de sua função primária e se tornou um "sistema de e-commerce informal". Perceba que diversos dos benefícios, funcionalidades e operações que um sistema efetivo de $e$-commerce ofereceria, a opção de usar Whatsapp não oferece. Entretanto, para estas organizações esta opção foi um diferencial para lidar com o fenômeno do isolamento social e da quarentena,

\footnotetext{
${ }^{3}$ https://opopularpr.com.br/compras-de-supermercado-pelo-whatsapp-cairam-no-gosto-popular/. Disponível em: 01/09/2021.
} 
esta é a abordagem em SI, de mãos dadas com os aspectos procedimentais, a organização adaptou seus processos e atendimento ao novo meio; e aspectos culturais, aproveitando a disseminação pervasiva já bem-estabelecida do aplicativo Whatsapp, os requisitos socioculturais de seus clientes, e a facilidade de atendimento da plataforma, e.g., uma pessoa analfabeta pode realizar uma operação neste cenário, basta enviar um áudio detalhando seu pedido, o que seria impossível em um e-commerce tradicional.

São diversos os vieses éticos neste cenário: (i) do negócio em utilizar o Whatsapp como veículo de compras; (ii) dos clientes de respeitar a quarentena e o isolamento social; (iii) dos funcionários do negócio, menos expostos a entidades externas e evitando possíveis aglomerações nas lojas; (iv) da empresa Facebook, em perceber que sua plataforma Whatsapp está sendo utilizada como operação de varejo e permitir que assim seja; (v) dos entregadores, que se colocam em risco para realizar as entregas; (vi) do governo, que perdeu a oportunidade de auxiliar ativa e instrutivamente os negócios à Transformação Digital; (vii) dos próprios serviços de $e$-commerce, que perderam espaço para outros aplicativos aleatórios, ao invés de implementar módulos de integração entre sistemas (sistemas de sistemas). Todas estas foram vertentes de ação cabíveis de ponderação de valores. Todavia, nem todas seguiram análises racionais e fundamentadas, pré-requisito básico para Ética [Fieser 2020, Ferraz 2014, Gibson 2014].

Neste trabalho consideraremos SI enquanto área, não analisaremos sistemas de informação especificamente, como tradicionalmente tidos. Nosso escopo primário é Ética, aqui indissociável de SI. Ademais, dos cinco cursos oficiais que compõe oficialmente a área de Computação no Brasil ${ }^{4}$, SI apresenta uma interdisciplinaridade e heterogeneidade mais adequado ao currículo suficiente e necessário para um diálogo com Ética. Mais do que isso, refletir sobre valores e não-neutralidade em SI, do pensar e do fazer.

Seguindo esta linha de raciocínio, na Seção 6.2.3 analisaremos, com propriedade, porque a episteme clássica e tradicional de CC é prejudicial à Ética Computacional, ou deficitária à Ética de forma geral.

Nosso objetivo nesta obra é propor alguns apontamentos sobre o atravessamento entre Ética e SI, na concentração do pensar-fazer. Isto é, está fora do nosso escopo tratar de Ética na epistemologia de SI. Por exemplo, não analisaremos os valores práticos da tripartite de aspectos proposto por [Stair e Reynolds 2018]. De forma iterativa, e interessante, encontramos diversos sistemas de informação que auxiliam na pesquisa em SI, e podemos analisá-los pelo viés de SI também, assim sucessivamente. Por exemplo, detectores de plágio, poucos são os detectores de plágio em Língua Portuguesa, prejudicando o uso por interessados sem determinado nível de letramento em Inglês, idioma dominante. Em certos casos os detectores de plágio online têm suas interfaces traduzidas automaticamente, gerando resultados repletos de erros na interface em Língua Portuguesa.

Esta obra está estruturada da seguinte forma: a Seção 6.2 traz as fundamentações teóricas mais específicas sobre Éticas e as áreas de aplicação aqui cobertas; na Seção 6.3 cobriremos aspectos éticos relacionados primariamente ao fazer; na Seção 6.4 cobriremos aspectos éticos relacionados primariamente ao pensar; a Seção 6.5 lida com alguns

\footnotetext{
${ }^{4}$ Ciência da Computação (CC), Engenharia da Computação (EC), Engenharia de Software (ES), Licenciatura em Computação (LC) e Sistemas de Informação (SI). [Brasil 2016a]
} 
extremos e casos polêmicos para criticar sensos comuns; e a Seção 6.6 apresenta a discussão final e conclusão.

\subsection{Fundamentação Teórica em Ética}

A Ética tem seus primórdios seminais na Grécia, a partir de pensadores como Sócrates, Platão e Aristóteles [Ferraz 2014]. Esta é uma visão hegemônica, por uma perspectiva de colonização, com foco na trajetória europeia e estadunidense. Extrapolando estas fronteiras, outros pensadores de locais diversos analisaram os valores associados às ações humanas, podemos citar na China, Confúcio e Lao Tzu [Gibson 2014]. Em África esta rastreabilidade se torna mais complexa [Gibson 2014, Gyekye 2010], algumas das razões são (i) a forte tradição da oralidade e transmissão de conhecimento por meios sem registro longínquo, e.g., escrita; (ii) resquícios de conflitos excessivos no continente que acarretaram em prejuízos socioculturais, e.g., guerras internas ou colonização radical; (iii) Ética, tal qual dialogamos, é um construto oriundo dos gregos, e diversos povos de África pensavam "Ética" de forma própria. Seria absurdo ou pejorativamente discriminatório conjecturar que os povos de África, continente plural, vasto e composto de diversos países, povos e nações, não debruçou-se à reflexão de seus próprios costumes, hábitos e tradições, com a possibilidade de que a vastidão de pensadores e estudiosos africanos partiram de pontos iniciais diversos e diferentes dos europeus/gregos. Por exemplo, um dos elementos africanos associados à Ética é Ubuntu [Gibson 2014]. [Gyekye 2010] é uma base inicial para adentrar o universo da Ética e Moralidade africana.

Este parágrafo introdutório teve o objetivo de esclarecer que parâmetros e indicadores associados à Ética variarão geográfica e espacialmente. Acostumados à Ética proveniente de raízes europeias e estadunidenses, operar e lidar com Filosofia Moral em espaços predominados por culturas externas a estas culminará na necessidade de apreender novas vertentes éticas.

Neste trabalho abordaremos a vertente dominante no contexto brasileiro, oriundo da Grécia e disseminado e aceito pelas fundações europeias e estadunidenses. Por exemplo, ao viajar para a China, há probabilidade de que não apenas as normas e ditames morais sejam diferentes, assim como as visões de ética em si. Com a globalização, velocidade e disponibilidade de acesso pelo mundo, você pode operar, e.g., trabalhar; em organizações em quase todo planeta Terra e alocado no Brasil. Outro exemplo, a Estônia oferece a possibilidade de residência eletrônica (e-Residency) ${ }^{5}$, e do Brasil você pode realizar diversas operações e procedimentos na Estônia, e na União Europeia. Neste caso concreto, é necessário pensar nas premissas éticas e morais estonianas de antemão.

Dada esta delimitação contextual, seguimos às fundamentações Éticas pertinentes.

\subsection{1. Ética}

Diversas são as definições de Ética, detalharemos e dialogaremos com a seguinte: "Segmento da filosofia que se dedica à análise das razões que ocasionam, alteram ou orientam a maneira de agir do ser humano, geralmente tendo em conta seus valores morais." 6 .

\footnotetext{
${ }^{5}$ e-resident.gov.ee/start-your-eu-company-with-e-residency/. Disponível em: 01/09/2021

${ }^{6}$ https://www.dicio.com.br/etica/. Disponível em 01/09/2021
} 
As fundamentações em Ética serão a partir de [Ferraz 2014, Gibson 2014, Fieser 2020, Deigh 2010] A Ética, também conhecida como Filosofia Moral, analisa as ações humanas e seus valores. Nos estenderemos na Ética propriamente dita, generalista, pois a mesma serve de alicerce e é aplicável às demais sub-categorias de Ética Aplicada que iremos tratar.

Um dos pensamentos seminais que seguem da Grécia à atualidade é associado a Aristóteles, a tripartite das faculdades humanas. Estas faculdades são composta por três níveis hierárquicos, desejo, emoção e razão. Nossas ações são orientadas por estes níveis, um diferencial entre os animais e seres humanos é a orientação e acesso ao nível mais elevado, onde animais estão restritos aos níveis de desejo e emoção. Por este mesmo motivo deixamos de atribuir valores às ações de animais, assim como responsabilização. Por exemplo, se um roedor mastiga a fibra ótica, o mesmo o fez estimulado por desejo ou emoção, não razão, sendo assim não há juízo de valor, i.e., ele não está errado, é mau ou injusto. Mesmo que essa ação desestabilize toda a Internet de uma cidade, ele tanto não refletiu eticamente sobre ela, assim como não é dotado de capacidade mental de fazê-lo posteriormente.

De forma breve e resumida, o nível do desejo envolve instintos e sensações; o nível da emoção envolve as subjetividade e sentimentos; o nível da razão envolve o que os filósofos consideravam o ápice da mente humana, tornando-se sábios. "O sujeito que age de forma moralmente correta, por seu turno, é aquele que permite que sua parte superior domine, isto é, sua razão" [Ferraz 2014], esta citação expõe como a linha grega predominante pensava na relação entre a Ética e a razão. Assim como coberto pela definição acima, a análise ética é a análise das razões, i.e., ela está acima das emoções e dos desejos. Atente-se que são "as razões", pois as pessoas arrazoam suas ações por razões tipificadas diferentemente [Deigh 2010].

Trazendo ao contexto de SI, quando interagimos com uma desinformação em uma RSO, podemos ser compelidos, por desejo ou emoção à compartilhá-la, entretanto a Filosofia Moral recomenda que a interação informacional seja regida pela razão. E mesmo que esta informação esteja em conformidade com nossa visão de mundo, apelativa aos nossos instintos, ou afinadas aos nossos sentidos, compartilhar esta informação de forma irracional é uma ação moralmente irresponsável. Por exemplo, compartilhar apenas pela chamada.

O sujeito da Ética é a Moralidade, composta pela Moral. Enquanto a moral é subjetiva e inerente ao indivíduo, a ética é objetiva e remete à coletividade. Cada indivíduo tem suas ações guiadas pelos seus valores morais no geral, como a definição aponta. A Ética analisa, a Moral age. Esta distinção é importante, pois a perturbação ética parte da moral, por exemplo, conforme o processamento de dados pessoais intensificou-se e começou a gerar impactos institucionais negativos graves, o debate ético rumou a institucionalmente considerar diversas práticas imorais. Este fenômeno associado à moralidade sobre o processamento de dados pessoais que motivou o surgimento da Lei Geral de Proteção de Dados (LGPD) [Brasil 2018a].

Nós refletimos sobre nossas ações a partir da ética. A ação, consciente ou inconscientemente, é guiada pela nossa moral primariamente. A Ética consiste da moderação entre a nossa moral, i.e., nossa subjetividade de valores; e a moral de terceiros, nor- 
malmente coletiva. A combinação desta moderação compartilhada entre os indivíduos compõe a moralidade. Conceitualmente, "antiético" não é uma qualidade, ao considerarmos que a ética é uma análise das ações, i.e., "não ética" (aética) é a ação realizada sem reflexão racional. Informalmente, podemos qualificar ações deliberadas e sistematizadas pela moralidade como imorais como antiéticas, e o mesmo para ações éticas. Por exemplo, um casal troca fotos de nudez em aplicativo enquanto namorados, e após o término uma das partes resolve deliberadamente vazar as fotos da outra parte na Internet. Neste caso, podemos considerar essa ação como antiética, pois a moralidade bem-difundida e estabelecida considera a mesma negativa. Isto é, dentro da flexibilidade de opções viáveis neste cenário, não há quase nenhum espaço para esta condução de valores.

Por exemplo, o caso dos termos de uso, políticas de privacidade e compartilhamento de dados do Whatsapp ${ }^{78}$. Sobre o aceite dos termos:

"Aceitando os novos termos, o usuário autoriza que o Facebook absorva informações das pessoas que utilizam o aplicativo para impulsionar a monetização de conteúdos nas redes sociais - ou seja, gerando anúncios mais personalizados, grande parte da renda da Facebook Inc, empresa que comanda as duas redes sociais." 7

“'Essa atualização da política de privacidade não chega a ser uma mudança de fato (nas regras de compartilhamento de dados). O que muda, na verdade, agora é que as pessoas perceberam que elas não tinham o direito de se opor ao compartilhamento dos seus dados enquanto elas estavam usando os serviços de WhatsApp', afirma Rielli." 8

Perceba que esta é uma ação deliberada, analisada e avaliada pela empresa. Não há necessidade ao funcionamento ou obrigatoriedade técnica para este compartilhamento de dados entre dois serviços computacionais diferentes. Isto é, o Facebook não depende dos dados do Whatsapp para operar, e vice-versa. E mesmo o argumento de que "melhora a experiência do usuário através de uma interoperabilidade de dados e melhoria em predições, perfilamento e recomendações" não se sustenta, porque é ausente ao usuário a opção de não compartilhar, i.e., ele é levado, por padrão, à esta opção porque o nãocompartilhamento é opção fora do padrão ou não disponível. Sendo assim, considerando que os usuários são titulares de seus dados, que a ação não é necessária aos requisitos primários das aplicações, que a LGPD indica que esta linha de ação é inadequada e que o usuário não tem poder sobre como são utilizados seus próprios dados, podemos pensar nesta prática com valores morais alinhados à antiética.

Dando prosseguimento, a Ética consiste de uma negociação dialógica entre as subjetividades morais do indivíduo, internamente; e das objetividades dos valores morais da realidade externos a ele. Este é um ponto filosoficamente demasiado complexo para

\footnotetext{
${ }^{7}$ https://www.opovo.com.br/noticias/tecnologia/2021/06/01/apos-polemicas-whatsapp-desiste-delimitar-aplicativo-para-quem-nao-aceitou-novos-termos.html. Disponível em: 01/09/2021

${ }^{8}$ https://www.uol.com.br/tilt/noticias/bbc/2021/01/13/novas-regras-para-o-whatsapp-4-perguntassobre-as-mudancas-no-aplicativo.htm. Disponível em: 01/09/2021
} 
ser detalhado aqui, entretanto entender a relação entre si e o meio é uma base essencial à Ética.

Por exemplo, você mora em um condomínio e, justificando necessidade de mais segurança, vai instalar uma "câmera inteligente" que vai sensorear e capturar as movimentações fora do seu apartamento, logo em cima da sua porta principal. As gravações serão armazenadas na nuvem e você terá acesso no seu computador e celular. Dito isso, seus vizinhos de porta concordam com a ideia de serem filmados? As pessoas que passam ou vão ao seu apartamento, concordam? O entregador do iFood tem o direito de solicitar que você apague os registros da aparição dele das suas gravações? Se a polícia requisitar essas gravações para investigar seu vizinho, você cede ou tem o dever de ceder? Se a gravação capturou seu filho quebrando uma janela do condomínio, aí ele mente dizendo que não foi ele e o próprio condomínio inicia uma investigação, você cede as gravações? Ou a integridade moral do seu filho está acima disso? Note que nenhuma dessas questões é trivial de refletir sobre, apesar de serem todas associadas à ética e que você deveria ter pensado sobre elas antes de comprar e instalar esse hardware.

Que tal pensarmos em um exemplo menos fantasioso? Uma Alexa ${ }^{9}$. Imagine ir na casa de um amigo e ter uma Alexa gravando o que vocês falam, ou um funcionário da Amazon escutando a conversa de vocês? Pior, com a possibilidade deste sensoreamento de áudio ser ativado "do nada"? Há alguns anos atrás essa opção seria considerada absurda, hoje muitos compram uma Alexa tendo consciência de que estarão jogando uma roleta russa com a sua privacidade. E não apenas com a sua, também com a de terceiros. Moralmente, os valores associados ao fenômeno de bem-estar enquanto "vigiado" ou "capturado" implicitamente está mudando. Eticamente, ainda nos cabe refletir sobre os valores morais associados com esta mudança de comportamento e possível paradigma.

Duas características da ponderação ética são necessárias aqui. A auto-preservação e a intenção própria. Argumentativamente, há uma necessidade racional de deliberarmos sobre individualismo e coletivismo. Ética não se trata apenas do que nós queremos, muito menos deve ser alinhada à nossa visão de mundo ou realidade; ao mesmo tempo a ética não deve ser um artifício de auto-depreciação ou coerção oculta ou latente. O indivíduo deve refletir sobre seu papel na comunidade coletivizada na qual participa, assim como a associação de suas predileções individuais neste contexto.

Dois extremos, "vou piratear este software porque se eu posso 'não pagar' por nada sempre, vou escolher esta opção" e "piratear software é desrespeitar toda a equipe de desenvolvimento, prejudicar toda uma indústria, dar um exemplo ruim para os outros e essa opção nunca deve ser sequer imaginada, por ninguém". Se você não tiver uma percepção ampla e heterogênea do dilema ético, e.g., pirataria; que está tratando, sua análise será comprometida por um viés e parcialidade restritos. Todas as nossas escolhas, e ações oriundas delas, são enviesadas e parciais, e isso faz parte da imanência em ser humano; o ideal, a partir da Ética, é de que haja uma minimização de ruído e de viés através de uma visão panorâmica e holística.

Um exemplo clássico externo à Computação, não é necessário fazer uma análise

\footnotetext{
${ }^{9}$ https://www1.folha.uol.com.br/tec/2019/04/empregados-da-amazon-ouvem-o-que-voce-diz-para-aalexa.shtml. Disponível em: 01/09/2021
} 
imparcial e neutra sobre o nazismo e "apontar o que o regime nazista fez de bom, correto e justo" para deliberar eticamente sobre o nazismo, o regime nazista, os nazistas ou os impactos e influência do nazismo. Apenas de repetir essa proposta em voz alta e refletir alguns segundos sobre ela já se percebe sua irrazoabilidade. Por este mesmo motivo que elementos de Memória Social, como estátuas, nomes de ruas, motivos culturais, símbolos, dentre outros, são proibidos de associação com elementos nazistas. Por exemplo, o caso de jogos onde uniformes de oficiais do regime nazista e suásticas são banidos [Garon 2018].

Finalmente, há a auto-preservação interseccional identitária enquanto pessoa inserida em uma comunidade ou sociedade desigual. Por exemplo, quando se trata de racismo algorítmico [Silva 2020] ou misoginia e machismo na comunidade de Computação [Ribeiro et al. 2020]. Nossas características étnicas, raciais ou de gênero fazem parte de quem somos, e negar isso é auto-anulação de um elemento de nossa subjetivação. Você pode ser motivado pelas ameaças à sustentabilidade social, inclusive a si mesmo, e por combater as desigualdade, seja em Computação, e respectiva comunidade, ou através da Computação, utilizando-a como artifício para esta empreitada. Entretanto, esta linha de abordagem ética precisa ser trilhada com cautela, porque podemos acabar guiados principalmente pela emoção ou desejo... e o pensar-fazer formal deve ser majoritariamente guiado pela razão, sem necessariamente desconsiderar desejos ou emoções.

Concluindo a fundamentação em Ética, este domínio apresenta suas próprias bases de fundamentação e princípios. A coleção de possibilidades para dialogar com Ética é vasta. A divisão tradicional separa a Ética em Metaética, Ética Normativa, Ética Aplicada e, mais recente, Ética Descritiva. Focaremos na Ética Aplicada, neste caso na Ética Aplicada à Computação e SI, caso necessário e oportuno, recorreremos às demais. Por exemplo, refletir eticamente sobre as especificidades e diferenciações entre a LGPD, no Brasil, e a General Data Protection Regulation (GDPR), na União Europeia (UE), é objeto da Ética Descritiva. Outros construtos aplicados inerentes à Ética serão cobertos na Seção 6.2.3, dedicada ao escopo principal desta obra.

\subsection{2. Ética Computacional}

[Johnson 2008] define Ética Computacional como: “O estudo das questões éticas que surgem como consequência do desenvolvimento e implantação de computadores e tecnologias de computação. Envolve duas atividades. Uma é identificar e colocar em foco as questões e problemas que se enquadram em seu escopo, a consciência da dimensão ética de uma situação particular. A segunda é fornecer uma abordagem para essas questões, um meio de aumentar nossa compreensão e encontrar maneiras de chegar a soluções sábias para esses problemas."

As fundamentações em Ética Computacional serão a partir de [Barger 2008, Johnson 2008, Masiero 2013, Spinello 2020, Baase e Henry 2017] e materiais ou cadernos de estudos sintetizados sobre o tema do Massachussetts Institute of Technology (MIT) ${ }^{10}$. A Ética Computacional, um dos ramos da Ética Aplicada, analisa as ações humanas e seus valores aplicadas do domínio da Computação. Fazendo uma analogia com Programação Orientada a Objetos, entre classes, Ética é uma super-classe, Ética Aplicada é uma sub-

\footnotetext{
${ }^{10}$ https://www.cs.uct.ac.za/mit_notes/ethics/. Disponível em: 01/09/2021
} 
classe da Ética, e a Ética Computacional é uma sub-classe da Ética Aplicada. Isto é, os níveis mais baixos herdam as características daqueles acima. Por exemplo, Privacidade é tanto um tema recorrente em Ética, quanto em Ética Aplicada, quanto em Ética Computacional. Um exemplo de tópico inerente à Ética Aplicada é a privacidade na relação profissional entre clientes e prestadores de serviços, a Ética Médica (outra sub-classe da Ética Aplicada) refletirá sobre dilemas diferentes da Ética Computacional.

Há, também, o debate sobre a Ética Computacional apresentar especificidades e propriedade enquanto sub-classe da Ética Aplicada, i.e., "O domínio de Computação tem dilemas especializados tais quais suas especificidades sejam passíveis de uma ramificação própria da Ética Aplicada? Ou são dilemas genéricos e não cabem ramificação específica?". Neste trabalho dialogamos com as percepções de [Johnson 2008] e com [Moor 1985], sendo este último um dos artigos seminais ao tema, e consideramos que a Ética Computacional tem relevância tal qual apresente especificidades e propriedades enquanto sub-classe da Ética Aplicada.

Sem prolongar de forma extensa, há uma incoerência na ideia de Ética Computacional enquanto restrita a juízo de fato, principalmente porque a Computação é uma atividade, também, social. Diferentes de fenômenos da natureza, por exemplo, artefatos e pensamentos computacionais não são "naturais". Isto é, se formos analisar Segurança em Tecnologia da Informação e Comunicação (TIC), devemos pensar em como a comunidade/sociedade dialoga com o conceito de segurança para, por exemplo, determinar parâmetros e critérios. Normalmente análises tratam dos cibercriminosos como "elementos etéreos", e.g., o e-commerce da Renner foi alvo de um ransomware ${ }^{11}$, este ataque não "veio do nada", isto é, para analisar este caso eticamente precisamos tratar de aspectos alheios aos técnicos. Caso a análise fique limitada aos aspectos técnicos, deixa de ser uma análise ética e recai em irrealidade, porque o conjunto de normas e os humanos envolvidos são elementos da realidade concretos envolvidos no caso.

É neste sentido que posicionamos SI, do leque de cursos oficiais em Computação [Brasil 2016a], como adequada para contemplar a Ética Computacional. E, neste sentido, é difícil conceber a ideia de que uma formação com o currículo de $\mathrm{CC}$, com pouquíssima ou nenhuma base de aspectos alheios ao técnico, instruirá ou conscientizará um especialista de forma a habilitá-lo na pluralidade e heterogeneidade que a premissa Ética pressupõe. O que não significa que hajam problemas éticos inerentes ao aspecto técnico, principalmente ao que tange juízos de fato, entretanto a possibilidade de viés ao pensamento de que "tudo se resume à técnica e o resto é secundário ou descartável" é maior, considerada a esmagadora maioria de episteme técnica.

No quesito da Ética e neste caso, cabe diferenciar juízo de valor e juízo de fato [Lacey 2006], de forma simples (i.e., deixaremos o debate kantiano de fora, por exemplo). O juízo de fato engloba a objetividade e o juízo de valor, subjetividade. Neste sentido, aspectos técnicos isolados são governados por juízo de fato. Por exemplo, a complexidade ou tempo de um algoritmo; taxa de transmissão de uma rede; capacidade de armazenamento de um disco rígido; ou quantidade de núcleos de um microprocessador. Isolados, estes elementos parecem "deslocados" de todos os elementos ou atributos cabíveis de val-

\footnotetext{
${ }^{11}$ https://www1.folha.uol.com.br/mercado/2021/08/renner-fica-mais-de-24-horas-com-sistema-fora-doar-apos-ciberataque.shtml. Disponível em: 01/09/2021
} 
oração moral. Entretanto, a pessoa, coletivo ou organização que pensou-fez estes itens são dotadas de valores morais; as consequências de impacto, influência ou aplicação destes itens envolvem valores morais, já que envolvem indivíduos; em certo nível consciencial, estes itens reforçam valores morais [Donia e Shaw 2021, Pereira et al. 2015]. Nenhum destes itens é elaborado ou desenvolvido para si, i.e., como fim; e só pensando nesta premissa já percebemos que a análise ética necessita de aspectos diversos. Sem estes aspectos diversos ela está isolada ao juízo de fato, isolada ao juízo de fato ela aliena o item de seu contexto, alienado do contexto não há Ética.

Considerando temas gerais de Ética Computacional, temos: (i) Privacidade, atualmente Proteção de Dados incluso; (ii) Cibercrimes ou Segurança; (iii) cyberbullying; (iv) Propriedade Intelectual; (v) Acesso Indevido; (vi) Aspectos Trabalhistas; (vii) Códigos de Ética ou Conduta. São alguns temas específicos por autores:

- [Barger 2008]: Internacionalismo; Robótica; Poder. Propõe um tópico chamado Computação Parasita (ou Parasítica) que diz ser "literalmente" inerente à Computação, i.e., não é generalizável para demais sub-classes de Ética Aplicada.

- [Johnson 2008]: Aspectos societários; Vigilância; Normatividade Digital (Ordem Digital).

- [Spinello 2020]: Poder; Liberdade de Expressão.

- [Baase e Henry 2017]: Erros, falhas e riscos; Liberdade de Expressão; Normatividade Digital (Avaliando e Controlando Tecnologia).

- [Masiero 2013]: Internet. O autor recorre a diversos casos, obras e tópicos de outros autores.

Nestas obras supracitadas não há distinção de alocação entre áreas acadêmicocientíficas distintas, e.g., Códigos de Ética e Conduta são oriundos da ES. O escopo adquire uma complexidade "frankensteiniana" e transdisciplinar, onde as fronteiras de onde começa a termina Ética Computacional são nebulosas e ambíguas. Por exemplo, [Masiero 2013] delimita a Ética Computacional ao excluir tópicos onde computadores apareçam de forma utilitária. Entretanto, na mesma obra, [Masiero 2013] instrumentaliza casos computacionais de forma utilitária. Por exemplo, o caso onde uma professora vê um aluno assistindo conteúdo pornográfico no computador.

Igualmente, nestas obras supracitadas, as análises práticas são baseadas em casos, em sua maioria reais. E estes casos não estão limitados à forma utilitária, ou limitados ao aspecto técnico, ou apenas a juízo de fato; eles estão relacionados com aspectos comportamentais e procedimentais. Se pensarmos no próprio tópico de Computação Parasita, de [Barger 2008], há transbordamento do aspecto técnico.

Este debate das fronteiras da Ética Computacional é bastante extenso para endereçarmos aqui, todavia há uma série de questões que emergem desta linha. O encaminhamento que conjecturamos adequado é da inter/transdisciplinaridade, i.e., para englobar a Ética Computacional com propriedade precisamos dialogar com outras áreas do conhecimento que não apenas a Computação pura. 
Por outro lado, há o juízo restrito, ou próximo de ser considerado restrito, do aspecto técnico isolado. Neste ponto podemos considerar os juízos de valor como secundários ou inadequados. Por exemplo, um código de software para funcionalidade $\mathrm{X}$ construído com linguagem de programação Y pode ser operacional e funcional. Entretanto, ele pode ter problemas técnicos, onde neste cenário podemos também analisar os valores morais de seu desenvolvedor. O mesmo ainda é um código ruim, apesar de não estar "errado". Esta ação de construir este código é passível de análise ética, distante de um juízo de valor e com maior proximidade de juízo de fato. Se este mesmo código de software fosse construído com linguagem de programação $\mathrm{Z}$, seria factualmente bem melhor para a funcionalidade $X$, o juízo sobre este artefato computacional é de fato. Paralelamente, podemos analisar o porquê da escolha do desenvolvedor pela linguagem Y, e não pela Z, e daí extrair um juízo de valor. Por exemplo, (i) "escolhi Y e não Z porque gosto mais da Y", agiu por afeição e não por razão; "escolhi Y e não Z porque não sabia da existência de Z", agiu por ingenuidade e ignorância do amplo aspecto técnico. Cabe lembrar, códigos de software não "desenvolvem a si mesmos" do nada.

Há uma precariedade de trabalhos formalmente, especificamente e explicitamente dedicados à Ética Computacional no Brasil, produzidos por brasileiros ou em português brasileiro [Carvalho et al. 2021b]. E uma das características, que prejudica este cenário, é de que diversas obras dedicadas à Ética Computacional são rotuladas como "Tecnologia e Sociedade", "Computação e Sociedade" ou "Aspectos Sociais da Computação" e similares. Um exemplo é [Ramalho 2013], com uma obra intitulada "Tecnologia e Sociedade" inteiramente dedicada à Ética Computacional. Apesar de não ser um demérito ou prejuízo de qualidade da obra, desvirtua-a de seu tópico primário. E, como já mencionamos aqui, uma análise da melhor qualidade plausível em Ética Computacional deve abarcar tópicos como "Sociedade" e "Aspectos Sociais", sem necessidade de uma significação terminológica ambígua.

Neste sentido, as obras supracitadas tratam da análise de casos externos ao Brasil, em grande maioria estadunidenses. [Masiero 2013], também, é fortemente ancorado em casos e apontamentos estadunidenses. Sobre o tema Ética Computacional, é limitada a quantidade de obras analisando casos brasileiros, assim como obras em português brasileiro produzidas por brasileiros.

\subsection{3. Ética em Sistemas de Informação}

Se já é desafiador e complexo encontrar fronteiras para Ética Computacional, i.e., onde a área começa e onde ela termina e o que ela engloba, com propriedade; esse cenário é intensificado ao refletirmos sobre Ética em SI. Como dito por [Bock et al. 2021]: "Ainda não há concepção ampla, coerente e aceita sobre como o campo entende a sua agenda ética, e o que deve ser coberto por esta agenda" [tradução nossa] ${ }^{12}$.

Nesta Seção nos baseamos em quatro Revisões Sistemáticas da Literatura (RSL) dedicada especificamente em Ética e SI: [Bock et al. 2021, Paradice et al. 2018, Stahl 2012, Mingers e Walsham 2010]. Estes trabalhos cobrem o tema com abrangência e oferecem uma abordagem bola de neve para trabalhos relacionados.

\footnotetext{
12"There is as yet no coherent and widely accepted conception of how the field understands its ethical agenda, and what it takes to be covered by that agenda”. [Bock et al. 2021]
} 
Além da ausência de concepção ampla, coerente e aceita, a partir destas quatro obras fomos incapazes de (i) encontrar um conceito consensual, sendo um aspecto negativo exclusivamente associado à apropriação categórica, sem ser um revés da argumentação ou conteúdo em si; (ii) perceber as diferenças entre Ética em SI e Ética Computacional. [Bock et al. 2021], em sua tentativa de diferenciação e categorização, anuncia que nenhum outro sub-domínio da Ética é devoto ao tópico principal da Ética em SI, que seria "desenvolvimento, uso e manutenção de sistemas de informação em/para ação social em sistemas organizacionais" 13 .

Considerando a definição de sistema de informação como exposta na Introdução e esta tentativa de restrição de escopo por [Bock et al. 2021], permanecemos incapazes de diferenciar Ética em SI de Ética Computacional, propriamente. Em sentido amplo, nos parece que Ética em SI é uma sub-classe ou irmã de Ética Computacional dedicada ao contexto organizacional, o que pode ser explicado pela recorrência de Ética Empresarial (Business Ethics). Esta, por sua vez, é uma sub-classe da Ética Aplicada que trata dos padrões organizacionais contemporâneos, seus princípios, conjuntos de valores e normas que governam as ações e comportamentos de indivíduos, ou grupos, em um ambiente organizacional formal [Moriarty 2021]. Considerada esta linha de raciocínio, a Ética em SI é uma combinação indissociável destas duas sub-classes.

Tendo a sua base e fundação ancorada nos Estados Unidos da América, país com uma forte tradição de organizações privadas, percebemos socioculturalmente disseminada a ideia de "Ética Empresarial" baseada em Empresa, definida como "Sociedade organizada para a exploração de indústria ou comércio; com a finalidade de obter um rendimento monetário através da produção de bens ou de serviços" ${ }^{14}$. Entretanto, a Administração Pública ${ }^{15}$ é constituída de organizações formais relacionando-se dialogicamente com sistemas de informação, assim como empresas. Definir uma "organização formal", por outro lado, é uma tarefa ainda mais complexa, e.g., um grupo estruturado em uma RSO, uma comunidade em um fórum online ou uma guilda em um jogo digital online, dentre outros. Se nos mantivermos restritos à ideia associada ao conceito de empresa, limitaremos o escopo de Ética em SI e corremos o risco, pensando pelo viés do Interacionismo Simbólico, de negligenciar ou ocultar o envolvimento de demais tipos de "organizações formais" perceptíveis. Principalmente Organizações Públicas, vinculadas à Administração Direta.

A partir de um viés crítico, convoca-se à uma maior importância e conscientização ética no domínio de SI e indica-se que este debate está aquém do esperado ou desejado. [Stahl 2012] anuncia que a comunidade de SI não atingiu seu potencial em relação ao tema e há uma carência de trabalhos em níveis mais elevados de abstração. $\mathrm{O}$ debate deve ultrapassar meras preferências morais, e deve ocorrer em conjunto com teorias éticas subjacentes. [Paradice et al. 2018] indica que mais casos de ensino e instrução são necessários, assim como mais cursos ou disciplina que lidam especificamente com dilemas de Ética Organizacional em contextos tecnológicos. Encoraja a elaboração de mais casos e cursos. [Bock et al. 2021] é, de longe, o mais crítico e incisivo nos resulta-

\footnotetext{
13،[...] development, use, and maintenance of information systems in and for the social action systems of organizations."

${ }^{14} \mathrm{https}$ ://michaelis.uol.com.br/moderno-portugues/busca/portugues-brasileiro/empresa. Disponível em: 01/09/2021

${ }^{15}$ pt.wikipedia.org/wiki/Administração_pública. Disponível em: 01/09/2021
} 
dos de seu artigo, onde indica que há relativamente pouca comunicação científica sobre Ética em Pesquisa em Sistemas de Informação (PSI); não há conceito unificado de Ética em SI; há pouco trabalho tanto sobre design de artefatos gerado por PSI quanto trabalhos empíricos. Isto é, há espaço e chamada de avanço no tema, e isso considerando que estes autores não cobriram trabalhos brasileiros ou o contexto brasileiro, onde há ainda menos casos registrados e estudados, cursos e comunicações científicas dedicadas.

O atravessamento entre o domínio da Ética e domínio de SI (ou Computação) requer um diálogo entre os conceitos, construtos e princípios de ambos. Para este fim, consideram-se mais adequadas três abordagens, (i) Deontologia, (ii) Teleologia ou Consequencialismo ou (iii) Ética das Virtudes ou Comunitarismo. Outras frentes fogem destas vertentes clássicas, como Floridi e a Ética da Informação [Tavani 2002]. Propõe atribuir ou transferir valor moral à solução computacional, de forma que a mesma é interpretada com devido protagonismo, ou até caráter de ator, e não como mera "ferramenta".

Vamos ser breves nas explicações destas três abordagens, que são tanto detalhadas nas obras de referência desta Seção, 6.2.3, como na Seção de Ética Computacional, 6.2.2.

Consequencialismo, e Teleologia, sustenta que o prejuízo/dano geral deve ser minimizado e o bem geral deve ser maximizado pelas ações corretas. Podemos pensar que são as consequências das ações que contam ou que as ações são julgadas com base no grau de bondade/bem que resultam. Esta linha é seguida por utilitarianistas, que podem ser baseados em duas vertentes: baseado em ação, julga as ações de indivíduos ou grupos; baseado em regras, julga os resultados da adoção de determinado conjunto de regras ao bem geral ou bem maior. Sendo uma linha simples de apreender as premissas iniciais, tem suas contrapartidas. No domínio da Computação, é bastante complexo prever ou antecipar as consequência de ações, principalmente em longo-prazo. Como o caso citado por [Spinello 2020], sobre a abertura da plataforma para desenvolvedores externos no contexto de jogos:

"Por alguns anos, a plataforma de desenvolvedor do Facebook hospedou vários jogos populares, incluindo Farmville e Candy Crush. Os clientes do Facebook concordaram em dar a esses desenvolvedores de jogos acesso aos seus dados em troca de jogar esses jogos. Porém, não havia proteções para o reaproveitamento desses dados coletados pelos desenvolvedores. Os algoritmos extraíam itens como mensagens e fotos dos usuários. Um desenvolvedor de jogos usou dados do Facebook para construir perfis não autorizados de crianças em seu próprio site. O Facebook permitiu o compartilhamento de seus dados de clientes sem um sistema para evitar abusos." ${ }^{16}$.

Deontologia, ao invés de tratar da consequência da ação, o foco está na ação em si. Enquanto o consequencialismo permite a ideia de "os fins justificam os meios", a deontologia repudia categoricamente este pensamento. Esta linha é idealista e baseada fortemente nas ideias do filósofo Immanuel Kant, que propôs o Imperativo Categórico. São

\footnotetext{
16"For a few years the Facebook developer platform hosted several popular games including Farmville and Candy Crush. Facebook customers agreed to give these game developers access to their data in exchange for playing these games. However, there were no protections for the reuse of these data collected by the developers. Algorithms were extracting items such as users' messages and photographs. One game developer used Facebook data to construct unauthorized profiles of children on its own website. Facebook had allowed for the sharing of its customer data without a system to prevent any abuses." [Spinello 2020]
} 
duas diretrizes, a máxima de que devemos ultrapassar a preocupação conosco e basear nossas ações aos outros; a máxima deve ser universal e aplicável a todos. Por exemplo, se considerarmos que mentir é errado, nunca devemos mentir, independente da circunstância. Isto é, consideremos um cenário de uma ditadura, se você for preso pelas forças ditatoriais e questionarem onde estão seus companheiros, você deverá falar a verdade, pois esta é a máxima moral.

Uma segunda vertente deontológica é baseada na ideia de contratos sociais. Estabelecemos contratos sociais com diversas entidades, entre elas o Estado. Neste sentido, coletivamente a sociedade mantém e protege os direitos dos indivíduos e os indivíduos protegem este contrato social, e as ações são julgadas em termos de manutenção e reforço destes direitos. Isto é, a premissa está baseada nos ditames deste contrato social e as consequências são secundárias, enquanto as determinações deste contrato social são a máxima. Nesta vertente, o mesmo se estende para termos de uso e políticas de privacidade em sistemas de informação, ao concordar com este contrato são estabelecidos os parâmetros morais.

Ética das Virtudes, ou Comunitarismo, trata de virtudes individuais ou coletivas. Nesta vertente o foco desvia da ação em si e desloca-se ao indivíduo ou coletivo específico. Deve ser alcançada uma elevação, consistindo do balanço entre extremos. Por exemplo, há um meio-termo entre sempre mentir e sempre falar a verdade e o ideal é alcançá-lo. A frônese (phrónesis) que nos permite balancear as virtudes, sendo a sabedoria prática ligada à dialética das ações. Aristóteles formulou a Éticas das Virtudes, sendo um empirista associou o alcançar a média áurea, este meio-termo, com a experiência e prática humana. Por exemplo, a Coragem está entre a imprudência e a covardia, devemos buscar sempre agir nesta intermediação, todavia em determinados momentos é possível que precisemos apelar a um ou a outro.

Alcançar a média áurea através da frônese, para Aristóteles, constitui no objetivo de vida a ser alcançado e mantido para o que chama de "uma vida boa e virtuosa". MacIntrye estendeu a proposta para uma abrangência comunitária, o foco da média áurea é individual e o comunitarismo é baseado em uma média áurea comunitária. Pela filosofia do Comunitarismo, as comunidades desenvolvem seus códigos e julgamentos éticos coletivamente através de socialização e consequente desenvolvimento. Comunidades diferentes geram suas próprias práticas e padrões e é impossível ultrapassar todas as tradições para um ponto de vista eterno e universal. Isto é, contextos específicos atrelados a comunidades específicas que são sempre relativos à "uma vida boa e virtuosa". A crítica principal à Ética das Virtudes e ao Comunitarismo é sua tendência à relativização. Em uma configuração multicultural e globalizada, a Ética Relativista pode oferecer desafios excessivamente complexos e perigosos.

Um exemplo de choque de valores morais ocorreu entre a plataforma Facebook e o Ministério da Cultura (MC) brasileiro, em um caso de $2014{ }^{17}$. O MC publicou uma fotografia de dois indígenas do grupo Botocudo em homenagem ao Dia do Índio, em sua página institucional na plataforma. Esta fotografia, exposta na Figura 6.1, mostra uma indígena de seios despidos. A plataforma excluiu a imagem argumentando que feria suas

\footnotetext{
${ }^{17}$ https://canaltech.com.br/redes-sociais/ministerio-da-cultura-acusa-facebook-de-censura-por-fotobloqueada-39633/. Disponível em: 01/09/2021
} 
políticas internas de publicações dos usuários. O próprio ministro da cultura entrou em contato com a plataforma e emitiu um comunicado: "tenta impor ao Brasil, e às demais nações do mundo onde a empresa opera, seus próprios padrões morais agindo de forma ilegal e arbitrária [...] fere a Constituição da República; o Marco Civil da Internet; o Estatuto do Índio e a Convenção da Unesco sobre Proteção e Promoção da Diversidade e das Expressões Culturais. Também desrespeita a cultura, a história e a dignidade do povo brasileiro". Posteriormente o Facebook reverteu a exclusão e bloqueio do conteúdo, entretanto foi causado um mal-estar. Apesar da discussão sobre a validade da decisão, se estava em conformidade com as regras da plataforma ou não, demonstrou como comunidades diferentes estabelecem e fazem valer valores morais diferentes.

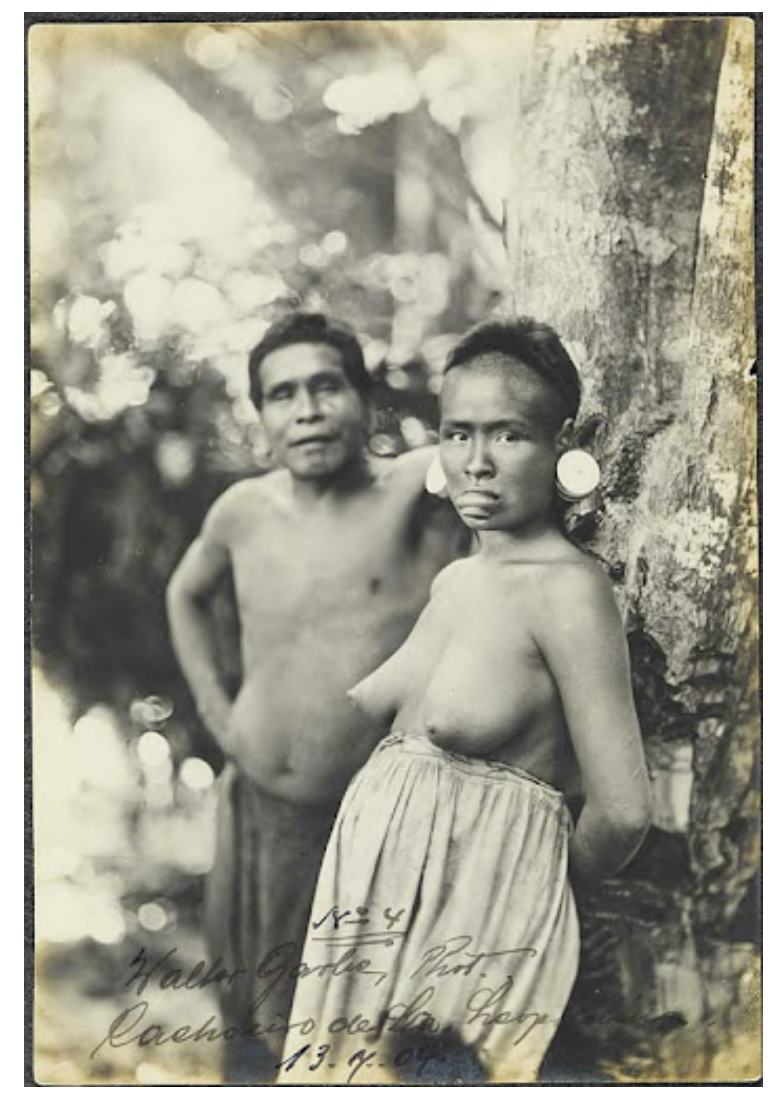

Figure 6.1. Indígenas da etnia Botocudo, por Walter Garbe [Garbe 1909]

Considerados os elementos conceituais e de fundamentação sobre Ética e SI, seguimos para as bases do pensar, a Ética em Pesquisa.

\subsection{4. Ética em Pesquisa}

O ser humano desenvolve pesquisas em todas as áreas do conhecimento e como as questões éticas associadas às novas tecnologias extrapolam as fronteiras da tecnologia e atingem a sociedade de maneira direta, existem fatores que estão diretamente relacionados às questões humanas. [Padilha et al. 2005] ressaltam que os pesquisadores estão atentos às questões burocráticas da pesquisa, como os termos, autorizações e aspectos operacionais para a realização da pesquisa, e muitas vezes, não dão a devida atenção ao seu elemento principal: o ser humano. 
É preciso garantir alguns aspectos relacionados diretamente com os participantes da pesquisa, sejam os pesquisadores, ou as pessoas que são o foco da intervenção de pesquisa. É importante garantir que nenhum desses indivíduos seja exposto a riscos desnecessários e nem que sofram algum tipo de discriminação. Para que isso seja contemplado no projeto é essencial que sejam adotadas metodologias, materiais e equipamentos adequados.

Diferentes métodos e metodologias de pesquisas são descritas na literatura e nem sempre consideram participações diretas de pessoas ou animais. [Cesário et al. 2020] consideram que a pesquisa cientifica opera em dois níveis, teórico e empírico. O nível teórico desenvolve teorias abstratas sobre um fenômeno social ou natural e o nível empírico está voltado a realizar teste dos conceitos teóricos para definir as observações da realidade. Os autores destacam que as abordagens das pesquisas podem ser quantitativas ou qualitativas. Em geral, as pesquisas quantitativas envolvem procedimentos experimentais, com resultados numéricos passíveis de comprovação estatística. Já as qualitativas consideram a bibliografia de uma área, estudos que coletam opiniões pessoais, observações com participação direta do pesquisador ou não, pesquisas etnográficas, dentre outras. Estas pesquisas podem ser analisadas de forma indutiva, entretanto, podem ter resultados transformados em números para uma análise mais representativa dos resultados.

Considerando as técnicas que envolvem a participação de pessoas, destacamos alguns modelos de pesquisas [de Pádua 2019]:

- Pesquisa experimental que avaliam os resultados da aplicação de procedimentos inéditos, ou não, em geral, de forma controlada, em que acontecem situações e ações baseadas em hipóteses bem fundamentadas. As pesquisas na área da Saúde exploram bastante este modelo;

- Pesquisa de levantamento de dados, que estuda o objeto da pesquisa em uma população e usa fortemente questionários fechados, ou entrevistas baseadas em roteiros. Este modelo é bastante utilizado nas pesquisas de áreas sociais e humanas. Mas, também é muito utilizado em avaliações de qualidade de software;

- Pesquisa com estudo de casos, que avaliam resultados de poucos objetos de pesquisa, considerando casos isolados ou pequenos grupos. Esta abordagem pode ser utilizada em muitas áreas e explora estudos com uma pessoa, ou grupo específico.

O pesquisador deve escolher a melhor estratégia para o fenômeno que quer estudar e que possa alterá-la de forma a atingir os objetivos de forma precisa. Os métodos adotados seguem etapas bem definidas, associadas à área da pesquisa que, em geral, consideram regras e modelos replicáveis.

Esse rigor científico vai gerar a confiança nos resultados obtidos, que serão passíveis de análises detalhadas, considerando pesquisas correlatas como fonte de comparação. E essa confiança está relacionada com o cuidado no levantamento, armazenamento e tratamento dos dados para que gere resultados relevantes para a sociedade.

Esse conjunto de práticas bem fundamentadas determinam resultados confiáveis, 
que respeitam diretrizes éticas, que respeitam a vulnerabilidade dos participantes e respeitam suas liberdades, garantindo que danos previsíveis serão evitados.

A Universidade Federal do Rio Grande do Sul (UFRGS) lançou um guia para integridade de pesquisas científicas, que descreve detalhes de vários aspectos contemplados sobre este tópico ${ }^{18}$.

\section{3. Ética fazendo Sistemas de Informação}

Esta Seção é dedicada ao "fazer" SI, em amplo espectro. Fazer SI ultrapassa o simples desenvolver ou construir código, como conduz o senso comum. De início, fazer SI envolve também hardware, armazenamento de dados e redes, assim como software; em seguida, demais elementos não-primários em relação com TIC e fundamentais ao fazer são considerados, como documentação (incluídos comentários em código), arquitetura empresarial, qualidade(s), relações inter-pessoais, versionamento, interação com o cliente ou usuário, aspectos políticos, precificação, dentre outros. Todos estes elementos estão fora do escopo de TIC propriamente dito, entretanto são essenciais ao fazer um artefato de TIC.

[Stair e Reynolds 2018] dividem SI em sentido amplo e em SIBC (Sistemas de Informação Baseado em Computador). Um SIBC obrigatoriamente terá TIC computacional, um SI não necessariamente. Por exemplo, é comum encontrar consultórios médicos ou de dentista brasileiros com os cadastros e dados pessoais dos clientes em papel, e.g., fichas pautadas; e estes também são sistemas de informação, por exemplo, estão sob auspícios da LGPD mesmo sendo meio físico. Nesta obra focamos em SIBC, com especificidades e complexidades específicas inerentes à Computação. Um SIBC contempla elementos computacionais de TIC (aspecto técnico) + pessoas (aspecto comportamental) + procedimentos (aspecto procedimental).

\subsubsection{Códigos de Ética}

Ética está relacionada com justiça social e vai além da lei, é o nosso compromisso com uma sociedade melhor. Um ambiente ético é criado efetivamente pelos valores cultivados pelas pessoas, prevalecendo atitudes com ênfase na honestidade, na palavra de cada pessoa, e no seu exemplo, com comportamentos de igualdade, justiça e confiança. No entanto, com o passar do tempo, podem ser criadas leis para inibição de comportamentos considerados prejudiciais à coletividade, e estabelecem-se penalidades para estes comportamentos, e.g., roubos ou assassinatos.

A Association for Computing Machinery (ACM) lista alguns princípios éticos gerais, moralmente intuitivos para muitos de nós ${ }^{19}$ : contribuir para o bem-estar humano e da sociedade, sabendo que todas as pessoas são partes interessadas à Computação; evitar danos; ser honesto e digno de confiança; ser justo e agir de forma a não discriminar; respeitar o trabalho requerido para produzir novas ideias, invenções, obras criativas e artefatos computacionais; respeitar a privacidade; honrar a confidencialidade. Mesmo sendo tão genéricos e aplicados à vida cotidiana, podemos estabelecer relações entre estas diretrizes e nosso comportamento enquanto profissionais e usuários de sistemas de

\footnotetext{
${ }^{18}$ https://www.ufrgs.br/propesq1/propesq/wp-content/uploads/2020/06/guia-para-integridade-empesquisa-cientifica.pdf. Disponível em: 01/09/2021

${ }^{19}$ https://www.acm.org/code-of-ethics. Disponível em: 01/09/2021
} 
informação.

Além dos princípios gerais que norteiam o bom funcionamento social, existe também a ética de determinados grupos ou locais específicos. Por exemplo, ética médica, ética profissional, ética empresarial, ética educacional, ética nos esportes, ética jornalística, ética na política, etc. Pensando na área de SI, como já mencionamos, não existe ainda uma "Ética" consolidada, observamos uma relação dialógica entre a Ética em Computação e os chamados códigos de ética, ou de conduta.

[Masiero 2013] explica que o profissional em Computação é quem projeta e desenvolve artefatos computacionais, produzindo os resultados de um processo de desenvolvimento de software: documentos de especificação de requisitos, modelos de análise e projeto, planos de teste, código fontes, manuais, planos de manutenção, dentre outros. Podemos acrescentar aqueles que trabalham com infraestrutura, redes e hardware de computadores em geral. Este profissional é normalmente qualificado através de cursos superiores de bacharelado em Computação, além dos cursos técnicos em Informática.

Sabemos então o que faz um profissional de Computação, mas esta profissão ainda não é regulamentada oficialmente no Brasil, e isso significa entre outras coisas que não há um código de ética formal para guiar a conduta destes profissionais. Código de Ética Profissional é um conjunto de normas éticas, que devem ser seguidas pelos profissionais no exercício de seu trabalho.

A maioria das profissões têm o seu próprio código de ética profissional derivadas da ética geral, e muitas vezes incorporado à lei pública. Nesses casos, os princípios éticos passam a ter força de lei. Perceba que, mesmo nos casos em que esses códigos não estão incorporados à lei, seu estudo tem alta probabilidade de exercer influência, por exemplo, em julgamentos nos quais se discutam fatos relativos à conduta profissional. Ademais, o seu não cumprimento pode resultar em sanções executadas pela sociedade profissional, como suspensão temporária ou definitiva do direito de exercer a profissão. Estes códigos são elaborados pelos respectivos Conselhos que representam e fiscalizam o exercício de cada profissão. Por exemplo, o Conselho Regional de Engenharia e Agronomia (CREA), e o Conselho Regional de Medicina (CRM). Então não existe um código de ética da Computação, com força de repressão institucional, pela ausência de um conselho regulamentando esta profissão.

No entanto, algumas organizações ligadas à área de Computação no mundo, tais como a ACM, o Institute of Electric and Electronic Engineers (IEEE-CS), desenvolveram projetos para criação de códigos de ética unificados. As recomendações oferecidas por estes códigos vão desde valores relativos ao interesse individual até importância para a sociedade em geral.

O código de ética da $\mathrm{ACM}{ }^{19}$ é mais geral e abrange também profissionais que atuam em hardware, infraestrutura e redes de computadores. Já o código de ética da IEEECS/ACM ${ }^{20}$ foi proposto em conjunto pelas duas entidades, e é voltado para a Engenharia de Software, e portanto, para profissionais que desenvolvem software.

[Anderson et al. 1993] também discutem em sua publicação o uso prático do

\footnotetext{
${ }^{20} \mathrm{https} / / /$ www.computer.org/web/education/code-of-ethics. Disponível em: 01/09/2021
} 
código da ACM. Considere visitar estes sites e ler atentamente os princípios, ou imperativos, definidos. Os principais personagens, a quem os códigos de ética se referem, são: profissionais de computação, sociedade em geral, usuários de sistemas, empregadores, empregados, clientes, colegas de trabalho e organizações. Uma das recomendações existente no código da ACM é: "Avaliar de forma abrangente e profunda os sistemas de computação e seus impactos, incluindo análise de riscos potenciais" [tradução nossa].

O Computer Ethics Institute criou os famosos 10 mandamentos da Ética Computacional ("The Ten Commandments of Computer Ethics" ${ }^{21}$ ). Esta lista resume as questões mais sensíveis que abrangem a Ética Computacional:

1. Não usarás um computador para causar mal a outrem.

2. Não interferirás no trabalho de computação de outrem.

3. Não bisbilhotarás os arquivos de computação de outrem.

4. Não usarás um computador para roubar.

5. Não usarás um computador para dar falso testemunho.

6. Não copiarás e nem usarás software proprietário pelo qual não tenhas pago.

7. Não usarás os recursos computacionais de outrem sem a devida autorização ou compensação.

8. Não te apropriarás do produto intelectual de outrem.

9. Considerarás as consequências sociais do programa que estás escrevendo ou do sistema que estás projetando.

10. Usarás sempre um computador por caminhos que garantam a consideração e o respeito pelos teus semelhantes.

\subsubsection{Propriedade Intelectual}

Propriedade Intelectual (PI), que compreende Direitos Autorais e Patentes, é um tema amplamente presente na literatura de Ética Computacional, arriscaríamos apontar sua presença em todas as obras do tema [Barger 2008, Johnson 2008, Masiero 2013, Spinello 2020, Baase e Henry 2017]. Sua importância acentuada se estende à SI, diretamente presente em [Stahl 2012]. PI, quando aplicada à Computação, é tópico-afim de SI, enquanto aspecto procedimental primariamente.

Aqui nesta Seção seguiremos uma abordagem crítica em relação à PI associada à SI. Em todas estas obras supracitadas a argumentação é favorável à PI, i.e., estão carregadas de valores morais enviesados e pré-concebidos. Sendo assim, nos parece que a essência da Ética é deturpada para uma normatividade moral conduzida. Se Ética trata de dilemas e PI é moralmente o ponto final e não há contra-argumentação ou viés contrário, então deixa de ser um dilema ético e se trata absoluto moral. Ser crítico, contrário ou

\footnotetext{
${ }^{21} \mathrm{http} / / /$ computerethicsinstitute.org/publications/tencommandments.html. Disponível em: 01/09/2021
} 
complementar a certas especificidades de PI é diferente de ser "absolutamente contrário" à PI. Ao contrário, as literaturas supracitadas expõe linhas argumentativas absolutamente favoráveis à PI e avessas a fenômenos conflitantes com este tópico.

O fenômeno popular que infringe a moralidade de PI é conhecido como "pirataria", formalmente rotulado de contrafação ${ }^{22}$. Plágio e contrafação são diferentes, neste sentido separamos os dois em categorias normalmente já separadas, contrafação em fazer e plágio em pensar. Em sentido amplo, ambos podem se manifestar independente da categoria de prática.

Considerando o foco contextual, países e blocos políticos específicos possuem legislações e moralidades diferentes ao tratar de objetos morais e ética. As obras supracitadas são fortemente ancoradas no cenário estadunidense, i.e., em determinado nível impossíveis de generalização ou transferência ao cenário brasileiro. Neste caso, algumas produções brasileiras se destacam no enfoque e profundidade do assunto, apesar de descoladas do tema da Ética Computacional. Recomendaremos alguns trabalhos abrangentes e posicionados no Brasil.

Em questão institucional, o Instituto Nacional da Propriedade Intelectual ${ }^{23}$ apresenta uma pluralidade de materiais e guias sobre o tema, atualizados. Capítulos de livro, [Nunes e Pinheiro-Machado 2017], "Propriedade Intelectual e Busca de Informação Tecnológica na área da Computação" e [Kon et al. 2020], "Direitos autorais, licenças e patentes". Em formatos diversos, o Almanaque para popularização de ciência da computação sobre Propriedade Intelectual ${ }^{24}$, como ilustrado na Figura 6.2. O website Um Caso de Arte ${ }^{25}$, do Instituto de Tecnologia \& Sociedade do Rio, com material do especialista em Direito Autoral Sérgio Branco.

Por outro lado, podemos também citar produções críticas a determinados aspectos ou à totalidade da situação atual da PI. As principais críticas tratam de desigualdades de privilégio e poder com ênfase em aspectos econômicos. [Marques 2016] aponta um caso concreto, da empresa Ultron na década de 1980, e critica a propriedade intelectual sob vieses colonizadores:

"Através dos direitos à propriedade intelectual, o primado da origem é mais ou menos sub-repticiamente evocado e traduzido para garantir o primado do centro sobre a periferia, da Europa sobre a América Latina, do primeiro sobre o terceiro mundo ou do 'colonizador' sobre o 'colonizado'." [Marques 2016]

Seguindo na linha de raciocínio de [Marques 2016], [Darch 2004] trata de como o fenômeno de Desigualdade Digital (Digital Divide) se relaciona com os países do Sul Global, como Brasil, apontando efeitos negativos da PI que os EUA e países da Europa impõe em sua respectiva agenda sobre o tema. Uma das saídas apontadas é o Software Livre, situando SI no olho do furacão. Enquanto este trabalho data de 2004, em 2021 ele

\footnotetext{
${ }^{22}$ https://jus.com.br/artigos/55180/notas-sobre-o-plagio-e-a-contrafacao/2. Disponível em 01/09/2021

${ }^{23} \mathrm{https} / / /$ www.gov.br/inpi/pt-br. Disponível em: 01/09/2021

${ }^{24} \mathrm{http}$ ://almanaquesdacomputacao.com.br/serie3baixa.html. Disponível em: 01/09/2021

${ }^{25}$ https://umcasodearte.com.br. Disponível em: 01/09/2021
} 

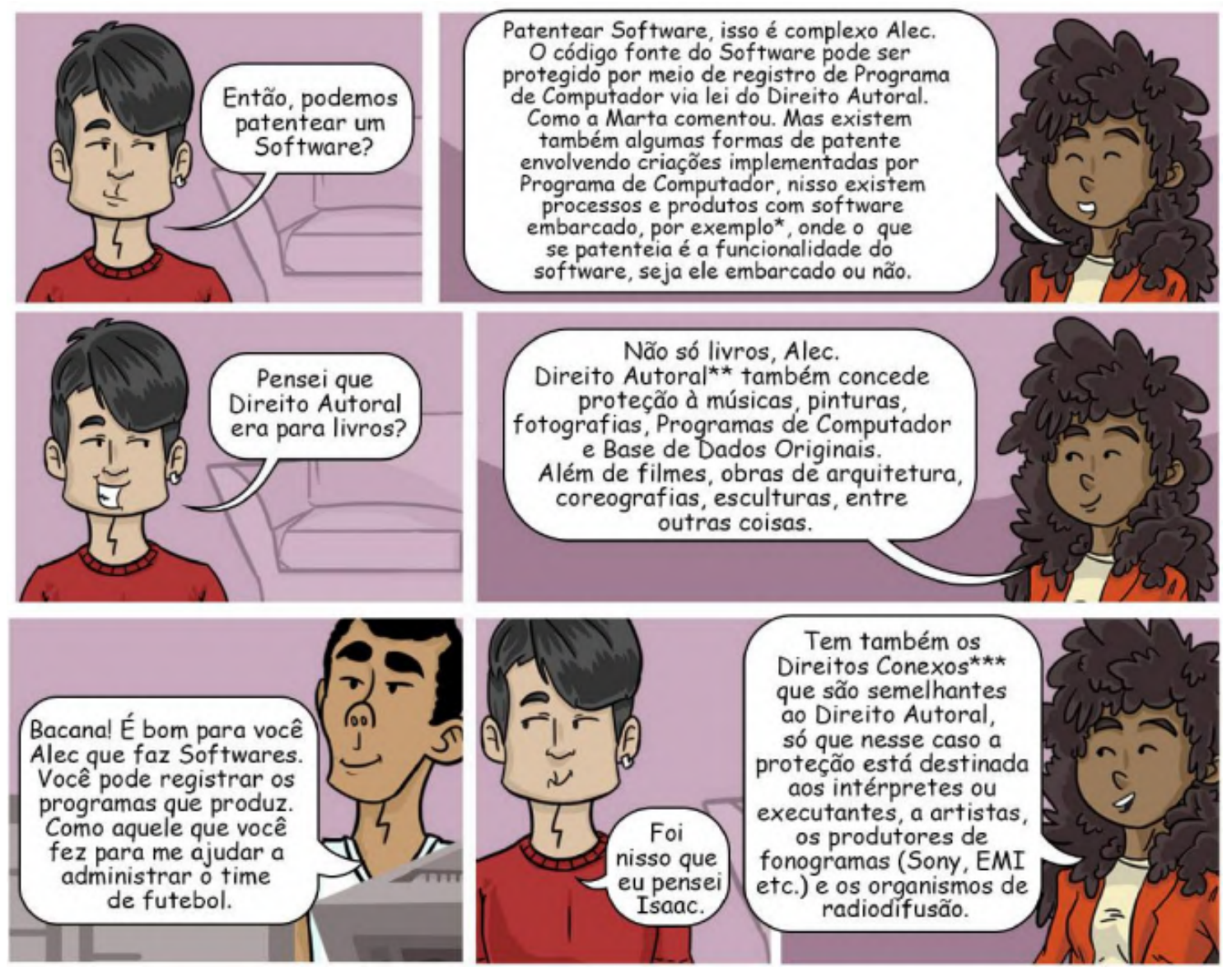

Figure 6.2. Recorte. Série 3: Propriedade Intelectual. Volume 11: Propriedade Intelectual no Comércio Eletrônico ${ }^{24}$

ainda é um tema em disputa ${ }^{26}$, tratando da indústria da produção acadêmica diretamente relacionada à PI e Ciência Aberta.

[Marques 2014] traz as teorias da Economia Política da Informação e do Conhecimento e o pensamento de Karl Marx para a discussão do papel da informação e do conhecimento na atualidade para propor um olhar crítico à PI. Defende a necessidade de debater as contradições do tema, pois os atores que participam da disputa discursiva enviesadamente e acriticamente defendem PI, financiados com recursos públicos, entre eles Governos e instituições de pesquisa e ensino. [Perelman 2003] também acompanha esta linha de raciocínio, indicando que a PI proporciona um mundo de litígios excessivos, violações intrusivas de privacidade, a destruição do sistema de ensino superior, interferência na pesquisa científica e uma distribuição desigual de renda.

Para concluir, um dos casos mais polêmicos envolvendo PI ocorreu na UE, tomando proporções transnacionais midiáticas em 2017. Em 2013 a UE encomendou uma ampla pesquisa, financiada com dinheiro público, sobre Direito Autoral (Copyright) e consequências de contrafação e pirataria ${ }^{27}$. As questões que nortearam o estudo foram: (i)

\footnotetext{
${ }^{26}$ https://www.timeshighereducation.com/opinion/push-open-access-making-science-less-inclusive. Disponível em: 01/09/2021

${ }^{27}$ https://edri.org/our-work/did-the-eu-commission-hide-a-study/. Disponível em: 01/09/2021
} 
Como as violações de direitos autorais online afetam as vendas de conteúdo protegido por direitos autorais? (ii) Quanto os infratores de direitos autorais online estão dispostos a pagar por conteúdo protegido por direitos autorais? ${ }^{28}$. Em resumo, o estudo conclui que a pirataria e contrafação são positivas à indústria da música, livros e jogos digitais; sendo negativa apenas à indústria de filmes, principalmente blockbusters. Fugindo do senso comum e da agenda moralista, é um discurso fora da curva para reflexão.

Neste sentido, o debate ético consiste da análise de lentes diversas sobre tópicos em disputa, evitando os extremos. Estes trabalhos críticos não necessariamente repudiam integralmente a base ou os conceitos de PI, sim trazem outros olhares, por perspectivas alheias à deontologia categórica, consequencialismo punitivo e ao idealismo determinístico tradicionais deste debate.

\subsubsection{Leis e normas}

A relação dialógica entre a moralidade e as tecnologias é complexa, de forma que nos ausentaremos desta profundidade. Brevemente, as tecnologias interagem com a sociedade ou coletividade e estas respondem às tecnologias, assim sucessivamente. [Moor 1985] debate a relação interativa entre a massa crítica deliberando criticamente em proporções cada vez maiores ou mais intensas e como este fenômeno afeta a moralidade, i.e., os valores morais estabelecidos e acordados entre a partes interessadas. Nesta Seção focaremos em normas jurídicas e técnicas.

De início, leis e normas têm relação direta com deliberação ética, explícita ou implícita, entretanto não é garantia de que sejam, efetivamente, morais. O exemplo clássico é relacionado à escravidão, em determinado momento histórico a escravidão foi legal, isto não significa que é escravidão é moral. Atualmente, escravidão é um dilema ético superado sem possibilidade de debate enviesado, enquanto outros dilemas atuais são relacionados com aborto, liberação animal, aquecimento global, desinformação, dentre outros. Isto é, seguir leis e normas não configura atitude ética, e agir eticamente não significa cegamente e literalmente seguir todas as leis e normas.

Neste sentido, determinadas leis podem ser negligenciadas via de regra, por diversas partes envolvidas, popularmente dizemos que a lei "não pegou". Como na lei de São Paulo ${ }^{29}$ que proíbe o uso de celulares em agências bancárias, e mesmo que pouquíssimos respeitem, os próprios sistemas bancários incentivam que os clientes usem celulares nas suas agências, para interoperação entre as aplicações do celular com os terminais eletrônicos, e.g., leitura de token para habilitar as operações de Pix no celular, como o cliente vai fazê-lo sem usar o celular na agência? Por que há esta funcionalidade implementada se a lei impede? Considerando que a lei serve apenas aos indivíduos, podemos considerar o banco conivente nestes casos?

Coletivamente, estabelecemos acordos morais entre nós. Por exemplo, quando as pessoas dividem e compartilham regras e critérios em casa, como respeitar os idosos, não falar palavrão, almoçar em determinado horário, limpar o próprio quarto, dentre outros. Em determinado momento podemos definir contrapartidas caso os acordos sejam des-

\footnotetext{
${ }^{28}$ https://netzpolitik.org/wp-upload/2017/09/displacement_study.pdf. Disponível em: 01/09/2021

${ }^{29} \mathrm{http} / / / \mathrm{g} 1 . g l o b o . c o m /$ bom-dia-brasil/noticia/2012/10/uso-de-celular-nos-bancos-e-proibido-masclientes-nao-respeitam-lei.html. Disponível em: 01/09/2021
} 
cumpridos, como ficar sem mesada, não comer sobremesa. E podemos definir "melhores práticas" para determinadas ações, por exemplo, a melhor forma de limpar as janelas, uma forma ideal de fazer o arroz, a melhor coleira para passear com o cachorro, como limpar a chupeta do bebê, dentre outros. A norma jurídica, i.e., lei; estabelece elementos de coerção para moldar o comportamento dos sujeitos através de imperativos de conduta, como se espera e deseja em uma célula da coletividade, e transgredir uma lei culmina em uma sanção [Bobbio 2019, Dimoulis 2016], é uma regra mandatória e punitiva. A norma técnica é "um documento, produzido por um órgão oficial acreditado para tal, que estabelece regras, diretrizes, ou características acerca de um material, produto, processo ou serviço. A obediência a uma norma técnica, tal como norma ISO ou ABNT, quando não referendada por uma norma jurídica, não é obrigatória" ${ }^{30}$.

Há uma diferença de reação entre uma lei (norma jurídica) e norma técnica. A transgressão de uma lei culmina em punição ou efeito negativo, a adequação e conformidade com normas técnicas culmina em potenciais recompensas ou efeitos positivos. Podemos perceber que a década de 2010 foi um período de intensificação da relação dialógica entre a computação, e seus impactos ou influências, com a tecnologia computacional no Brasil. Uma das leis resultantes é a Lei Geral de Proteção de Dados (LGPD) [Brasil 2018b]. Em relação a juízos de valor e juízos de fato, normas técnicas são fortemente associadas a juízos de fato; enquanto leis, juízos de valor. Um exemplo de norma técnica associada à LGPD é a família de normas da ISO/IEC $2700{ }^{31}$, com foco em Sistema de Gestão de Segurança da Informação, sendo a ISO 27001 passível de certificação regulamentada e as demais recomendações de boas práticas. Determinadas relações interorganizacionais formais dependem da conformidade com normas técnicas, e certificações são formas bem-estabelecidas de expor que se seguem as diretrizes determinadas pela norma.

Existem diversas interpretações e críticas sobre a relação entre as leis e a sociedade. Em sua maioria, a literatura relacionada à Ética Computacional é parcial favorável a leis e normatizações mandatórias [Johnson 2008, Baase e Henry 2017]. Pensando pelo viés da Teoria do Conflito e com uma visão crítica, [Mascaro 2013] associa a normatização jurídica, tanto formulação quanto estrutura, ao estado burguês e manutenção do sistema capitalista. No Estado burguês, as leis são pensadas para privilegiar os detentores e favorecidos pelo Capital, e manter a estrutura dominante para uma minoria. Por exemplo, em versão inicial a LGPD definia que decisões automatizadas poderiam ser revisadas por revisão humana caso solicitado, algum tempo depois houve uma alteração crucial, as decisões automatizadas seriam revisadas de forma também automatizada. A decisão foi criticada por especialistas ${ }^{32}$, considerada um retrocesso ao avanço esperado pela lei:

"Enfim, considerando a ausência de transparência e os efeitos perversos das análises exclusivamente automatizadas, a revisão humana acerca das decisões tomadas a partir de dados pessoais é uma salvaguarda constitucional e democrática que tenderia a

\footnotetext{
${ }^{30}$ https://pt.wikipedia.org/wiki/Norma_técnica. Disponível em: 01/09/2021

${ }^{31}$ https://pt.wikipedia.org/wiki/ISO_/IEC_27000. Disponível em: 01/09/2021

${ }^{32} \mathrm{https}: / / \mathrm{www} . c o n j u r . c o m . b r / 2019-$ set-09/constituicao-poder-importancia-revisao-humana-decisoesautomatizadas-lgpd. Disponível em: 01/09/2021
} 
evitar danos aos cidadãos mais carentes que não possuem outro acesso a bens que geram cidadania e ficam dependentes da análise do "sistema".

$\mathrm{Na}$ era da tecnologia, é preciso realçar a importância do direito à explicação e à revisão humana das decisões automatizadas que impactam a vida das pessoas.

Desta feita, tendo em vista o atual estado da arte, o veto presidencial se revela um grave equívoco de entendimento político acerca da importância da obrigatoriedade da revisão humana. Pelo menos até que as IAs evoluam e possuam demonstrar de forma segura as motivações de suas conclusões, sujeitando-se a algum tipo de controle." 32

Neste sentido, refletimos sobre a relação e influência de agentes que operam em favor do Capital, como bancos e agentes do mercado financeiro, que poderiam ter perdas ou riscos financeiros substanciais com a obrigatoriedade da revisão humana. Uma preocupação das empresas em relação à conformidade, adequação e aderência às leis é pela gestão de sua imagem institucional [Bioni 2019], e neste momento de ascensão do debate sobre racismo algorítmico [Silva 2020] é demasiado arriscado ser rotulado como uma empresa opressora e racista através de suas operações automatizadas, e envolver atores humanos nestes casos culmina na possibilidade de erros comunicativos ou envolvimento de subjetividades humanas, impossíveis considerando atores computacionais.

Podemos esperar uma profusão de normas jurídicas relacionadas à Computação, e sua aplicação, na década de 2020. Já no início temos a "Lei das Fake News" (PL 2630/2020) 33; ou a PL 21/2020, que "Estabelece princípios, direitos e deveres para o uso de inteligência artificial no Brasil, e dá outras providências" ${ }^{34}$. Aprovadas ou não, demonstram a preocupação associada à moralidade relacionada com estes dois fenômenos da computação, seja desinformação desenfreada ou inteligências artificiais opacas ou nocivas à sustentabilidade social.

Assim como a Lei Sarbanes-Oxley (SOX) ${ }^{35}$ influenciou o cenário computacional transnacional na década de 2020 [Mingers e Walsham 2010], a LGPD está influenciando o período atual desta obra. Tão abrangente e pervasiva, a LGPD é um marco para o processamento de dados e proteção dos mesmos. Se associarmos a LGPD [Brasil 2018b] com a definição de sistema de informação [Stair e Reynolds 2018], observamos que ambas são indissociáveis, tanto no pensar quanto no fazer.

Nos ausentamos de uma profundidade analítica técnica sobre a LGPD, considerando que há uma abundância de obras dedicadas ao tema. Entretanto, há uma carência de obras técnicas se comparada com a quantidade de obras contextuais e conceituais. Sobre a LGPD, de forma ampla, recomendamos as obras e cursos do Instituto de Tecnologia e Sociedade do Rio de Janeiro (ITS Rio) ${ }^{36}$ e Data Privacy BR ${ }^{37}$. São encontrados cursos e obras gratuitos e pagos, com certificado.

\footnotetext{
${ }^{33}$ https://www25.senado.leg.br/web/atividade/materias/-/materia/141944. Disponível em: 01/09/2021

${ }^{34}$ https://www.camara.leg.br/propostas-legislativas/2236340. Disponível em: 01/09/2021

${ }^{35}$ https://pt.wikipedia.org/wiki/Lei_Sarbanes-Oxley. Disponível em: 01/09/2021

${ }^{36}$ https://itsrio.org/pt/home/. Disponível em: 01/09/2021

${ }^{37}$ https://dataprivacy.com.br. Disponível em: 01/09/2021
} 


\subsubsection{Tomada de Decisão Ética em SI}

[Moor 1985] discute que um problema típico na Ética Computacional surge porque existe uma lacuna política sobre como a tecnologia computacional deve ser usada. A computação nos oferece novos recursos e estes, por sua vez, nos dão novas opções de ação. Políticas de conduta para diversas destas situações ou as políticas existentes são inexistentes ou inadequadas. Desta forma, uma tarefa central da Ética Computacional é determinar o que devemos fazer nesses casos, i.e., formular políticas para orientar nossas ações. Uma outra dificuldade é que, juntamente com a política, existe uma lacuna conceitual. Embora um problema na Ética Computacional possa parecer inicialmente claro, uma pequena reflexão pode revelar um conflito conceitual. O que é necessário em tais casos é uma análise que forneça uma estrutura conceitual coerente dentro da qual formular uma política de ação [Moor 1985].

Desde o ano 2000, [Bynum 2000] já faz uma reflexão sobre o futuro do desenvolvimento tecnológico. No futuro, como resultado da invenção de máquinas "imitadoras da vida", haverá mudanças dramáticas nas políticas e práticas sociais, na lei, na economia e nas relações humanas. Considere, por exemplo, algumas das implicações econômicas dos autômatos computadorizados. O desenvolvimento de tais máquinas "dá à raça humana uma nova e mais eficaz coleção de escravos mecânicos para realizar seu trabalho". Mas o trabalho escravo efetivamente elimina muitos empregos humanos, tornando as pessoas sem valor no mercado de trabalho. Mesmo o trabalho intelectual de um cérebro humano não está imune à substituição por máquinas. Se construirmos máquinas "cujas capacidades intelectuais duplicam as dos seres humanos", quais serão as consequências sociais e éticas? Será que tais máquinas têm um propósito próprio que rivaliza com o dos humanos? Eles terão o direito de "florescer" e ter "princípios de justiça" como os humanos? Será que máquinas cujas capacidades intelectuais excederem as dos seres humanos terão direitos que, portanto, sobrepõem-se aos direitos humanos? Estas são apenas algumas das questões éticas óbvias que surgiriam da existência de tais autômatos [Bynum 2018].

Percebemos, por estes exemplos, questões em SI cabíveis de atenção. É complexo proceder diante de determinadas polêmicas ou discussões, então para ajudar no raciocínio sobre estes assuntos, [Laudon e Laudon 2020] sugerem um passo-a-passo para deliberar sobre questões éticas em Computação que pode ser bastante útil na prática. São eles:

1. Identifique e descreva claramente os fatos: descubra quem fez o quê, quando e como; a visão correta da situação ajudará a encontrar uma solução.

2. Defina os conflitos ou dilema e identifique os valores envolvidos: uma questão ética envolve direções de ação opostas que envolvem valores importantes (por exemplo, liberdade, privacidade, proteção de propriedade, etc.)

3. Identifique os interessados: observe quem são os personagens interessados no desenlace da questão ética.

4. Identifique alternativas razoáveis a adotar: liste opções possíveis para o desfecho da questão (que nem sempre vão satisfazer a todos os interessados). 
5. Identifique potenciais consequências das suas opções: questione-se o que ocorreria ao longo do tempo com cada uma das alternativas listadas.

A sua deliberação sobre uma questão ética é completa ao utilizar todos os elementos coletados e produzidos neste passo a passo para, então, adotar sua posição. Neste momento, talvez você precise tomar como base algum(ns) princípio(s) filosófico(s). No âmbito filosófico, os princípios, enquanto regidos pelas leis morais, são valores que o indivíduo considera adotar de acordo com o que diz sua consciência. Alguns exemplos são: Idealismo, Realismo, Pragmatismo.

Para o idealista, a bondade é encontrada na perfeição, no imaterial ou ideia de alguma coisa; e o mal é a distorção do ideal. Portanto, imperativos éticos nunca podem mudar. Idealistas julgam a ação em si e não suas consequências. Como estabelecer uma fundamentação moderna para a ética que seja, simultaneamente, atemporal e universal (válida sempre em todos os lugares)? Se uma ação não é correta para todos, então não é correta para ninguém. Se todos fizessem isso, a organização ou sociedade poderiam sobreviver? Immanuel Kant é um exemplo célebre de idealista.

Para o realista, todo conhecimento é obtido através dos sentidos. A bondade é encontrada ao se viver uma vida de virtude em harmonia com a natureza. O homem em estado natural é governado pelas leis da natureza onde todos são iguais e nenhum indivíduo deve prejudicar o outro. Tem o direito de usar a força para defender os seus direitos, mas não para ferir os direitos dos outros indivíduos. Seu direito termina quando começa o do outro. John Locke é um exemplo célebre de realista.

Para o pragmático, a realidade é um processo, mudança. Acontecimento, ou seja, experiência. $\mathrm{O}$ valor de algo é determinado unicamente em termos de sua utilidade para alcançar algum fim. Portanto, o fim justifica os meios. Princípio da Utilidade: a ação dotada de "maior valor ético" é aquela que maximiza a felicidade geral e minimiza a dor; Cálculo que visa o maior benefício para o maior número de pessoas (maximização do prazer). Realize a ação que produza a melhor relação custo/benefício. John Stuart Mill é um exemplo célebre de pragmatista.

Indo um pouco mais além, para [Laudon e Laudon 2020], "a introdução de nova tecnologia de informação tem o efeito de ondas concêntricas que suscitam novas questões éticas, sociais e políticas, as quais precisam ser tratadas nos níveis individual, social e político". Eles explicam que questões éticas estão conectadas a questões políticas e sociais e se propaga nos níveis individual, da sociedade e do estado.

[Laudon e Laudon 2020] ressaltam que cinco dimensões morais nos questionam sobre a presença dos Sistemas de Informação e da TI na sociedade atual. (1) Direitos e obrigações sobre a informação: que direitos sobre a informação relativa a si próprios os indivíduos e organizações possuem?; (2) Direitos e obrigações sobre a propriedade: como os tradicionais direitos de propriedade intelectual serão protegidos em uma sociedade digital?; (3) Prestação de contas e controle: quem deverá prestar contas e ser responsabilizado por danos causados aos direitos individuais e coletivos sobre a informação e propriedade?; (4) Qualidade do sistema: que padrões de qualidade de dados e sistemas devem ser exigidos para proteger os direitos individuais e a segurança da sociedade?; (5) Qualidade de vida: que valores devem ser preservados em uma sociedade baseada na informação e con- 
hecimento? Quais instituições devem ser protegidas contra a violação? Que valores e práticas culturais são apoiados pela nova tecnologia de informação?

\section{4. Ética pensando Sistemas de Informação}

Esta Seção é dedicada ao "pensar" SI, em amplo espectro. Desenvolvemos sistemas de informação simultaneamente enquanto pensamos, aqui lidamos com o pensamento consciente, englobando estudos, ensaios, entre outros. Pesquisar SI consiste em analisar a realidade envolvendo os três aspectos conceituais contidos na definição da disciplina.

Enquanto área, são encontradas inconsistências e incoerências entre cursos de universidades, cidades, regiões e países diferentes [Kohun et al. 2012], a "identidade" que SI assume também está associada à entidade que lhe concebe. Por exemplo, um colegiado formado majoritariamente por cientistas da computação que aprova a criação de um curso de SI em seu departamento tem maior probabilidade de produzir um currículo ancorado em aspectos técnicos; uma faculdade de Administração, terá maior probabilidade de produzir um currículo ancorado em aspectos procedimentais. As três possibilidades, associadas aos três aspectos atribuindo-lhe maior peso, são válidas e consistentes com a essência de SI. Propomos analisar a história e currículo de diversos cursos de SI espalhados pelo Brasil para ver como os mesmos podem diferenciar substancialmente, oficialmente aprovados como SI.

Por outro lado, pesquisas atravessando Ética e SI ainda são escassas [Bock et al. 2021]. No cenário brasileiro, a principal conferência dedicada ao pensar SI, o Simpósio Brasileiro de Sistemas de Informação (SBSI), reforça esta escassez e abandono do tema, sem trabalhos dedicados primariamente ao tópico e com uma deficiência alarmante de aspectos éticos entremeados, de forma não-primária (como ocorrência de Comitê de Ética) [Carvalho et al. 2021c].

\subsubsection{Plágio}

Plágio é a "ação ou efeito de plagiar, de expor ou de mostrar uma obra intelectual de outra pessoa como se fosse de sua própria autoria", ou ainda, "apresentação que alguém faz de algo, como se fosse de própria autoria, quando na verdade foi criado ou pertence a outrem; cópia, imitação: plágio de um livro, trecho de música, de uma pintura etc" 38 . O plágio é uma das mais importantes questões éticas no meio acadêmico, e portanto, em pesquisas em Sistemas de Informação.

Quando falamos em plágio na área acadêmica, normalmente nos referimos ao fato de alguém (professor, aluno, pesquisador) apresentar como de sua autoria, um texto, gráfico, imagem ou qualquer outro tipo de produção intelectual de outra pessoa, seja em todo ou em parte, sem o devido crédito. No caso do plágio acadêmico, existem diversos tipos. O plágio direto ocorre na forma da cópia literal do texto original, sem referência ao autor e sem indicar que é uma citação. Já o plágio indireto é uma reprodução, com as próprias palavras, das ideias de um texto original sem a devida indicação da fonte. Um caso bastante discutido também é o chamado auto-plágio, que ocorre quando um autor reapresenta, como se fosse original, um trabalho ou parte significativa de um trabalho, de

\footnotetext{
${ }^{38}$ https://www.dicio.com.br/plagio/. Disponível em: 01/09/2021
} 
sua própria autoria. Apesar de mais difícil de ser percebido, além desses tipos, também pode ser considerado plágio o uso de uma ideia com elementos muito parecidos com o original, ou seja, plágio de um conceito.

Além do dilema ético envolvido, plágio é um crime previsto em leis. Por exemplo, a violação dos direitos autorais prevista no artigo 184 do Código Penal ${ }^{39}$. O sujeito que comete plágio também pode ter que se retratar em público; e, por exemplo, no caso de um aluno, o ato pode levar à reprovação ou desligamento da instituição, e no caso de pesquisadores, inclusive professores, pode levar à demissão.

A Cartilha Sobre Plágio Acadêmico da UFF, disponível online ${ }^{40}$, apresenta detalhes sobre esse problema ético de forma clara e concisa, e dá a dica fundamental de como evitá-lo: “[...] basta escrever com suas próprias palavras de modo a explicar todas as citações, apresentar as fontes no próprio texto, e, se necessário, incluir as citações diretas (texto literal do autor utilizado) à medida que o trabalho vai sendo desenvolvido". Desta forma, ao citar corretamente, você não vai cometer plágio. É importante também ressaltar que existem normas, tais como, NBR 10520:2002 e NBR 6023:2002, da Associação Brasileira de Normas Técnicas (ABNT) ${ }^{41}$, que indicam as formas corretas que realizar as citações.

Plágio não está restrito a texto, figuras ou tabelas. Há também o plágio de código de software [Đurić e Gasevic 2013], tanto em ambiente acadêmico formal quanto científico, i.e., trabalhos acadêmicos ou artigos científicos. Por exemplo, um aluno desenvolve um software para uma disciplina e um ano depois cede este software para um colega utilizar o mesmo, idêntico, o que configura plágio; cientificamente, apropriar-se de código de software de outrem sem a devida citação e referenciação e publicar comunicação científica a partir do uso do mesmo, reivindicando autoria original para si. Bases de dados também são passíveis de plágio [Nunes e Pinheiro-Machado 2017], sem a devida citação e referenciação de uma base específica por culminar em conflito ou disputa judicial. Não há um costume de registrar código de software ou bases de dados para formalização de autoria, principalmente no meio da Computação. Podemos conjecturar que isto se dê porque na formação em Computação este tópico é ignorado, posto de lado ou considerado irrelevante de obrigatoriedade curricular; e que não haja uma cultura consolidada sobre estes elementos, principalmente no meio acadêmico.

Com a facilidade propiciada pela Computação, dados ou informações explicitamente estruturados estão amplamente disponíveis, basta um "Ctrl + c, Ctrl + c" (copiar e colar) para apropriar-se do texto de outros autores, ou do próprio. Ao mencionarmos a complexidade e heterogeneidade da Ética, ressaltamos que nem sempre o plágio é "individual" e que ocorre em uma cadeia de responsabilizações. Por exemplo, um orientador acadêmico que permite que um orientado siga para uma banca de defesa de monografia sem debate ou preocupação relacionada à plágio; uma conferência que permite trabalhos apresentando plágio explícito e não promove auto-reflexão sobre o fenômeno; um professor que descobre que um grupo de estudantes comete plágio entre si, e ignora ou não interfere educacionalmente.

\footnotetext{
${ }^{39}$ http://www.planalto.gov.br/ccivil_03/leis/2003/110.695.htm. Disponível em: 01/09/2021

${ }^{40} \mathrm{http}$ ://www.noticias.uff.br/arquivos/cartilha-sobre-plagio-academico.pdf. Disponível em: 01/09/2021

${ }^{41}$ http://www.abnt.org.br. Disponível em: 01/09/2021
} 


\subsubsection{Ciência Aberta e Transparência}

Seguiremos as obras de [Pontika et al. 2015] e [Elliott 2020] nestes tópicos. Apesar da predominância de ideias positivas sobre estes tópicos, a deliberação ética deve ultrapassar uma agenda enviesada. Por exemplo, Transparência, assim como Ética, é um dos termos associados a valores clichês que todos os indivíduos ou organizações dizem apoiar ou defender simbolicamente, só que concretamente pouquíssimos apoiam ou investem ativamente, limitados ao campo discursivo de moralismo imaginário. Habilitar e gerenciar transparência culmina em consequências positivas e, contrariando o senso comum, negativas. Obviamente, Transparência é um dos requisitos básicos para uma sociedade democrática, só que ela não vem sem custos, para implantação ou consequenciais. Como indicam [Bannister e Connolly 2011], iniciativas de transparência resultam em aumento do escrutínio crítico em relação às atividades ou dados, permissibilidade para auditoria enviesada ou inescrupulosa, e abertura de dados que podem servir para agendas políticas escusas.

Um exemplo baseado na vivência profissional do primeiro autor. Em determinado momento participei de uma comissão dedicada à transparência na Universidade Federal do Estado do Rio de Janeiro (UNIRIO) e em certa reunião foi exposto um caso associado com um dado que obrigatoriamente deve ser aberto, a agenda do Reitor. Antes, a agenda do Reitor era integralmente transparente no devido sítio eletrônico. Em um período de perturbação política manifestantes rastrearam a agenda do Reitor, identificando hora e local, e lançaram ovos no carro oficial do mesmo. Nos ausentamos da análise ética deste episódio específico, pois foge do domínio de SI primariamente. Todavia, os dados transparecidos foram reavaliados, e a agenda do Reitor deixou de expor hora e local, indicando apenas o compromisso e respectiva parte do dia. Este é um exemplo relativamente inofensivo e ilustra como o mito da "transparência absoluta de tudo a todo momento" nem sempre é positivo.

A Figura 6.3 expõe uma taxonomia de Ciência Aberta de forma panorâmica. Observando-a podemos notar uma pluralidade de dados e informações associados com o conceito, agenda e agência da Ciência Aberta. Dados Abertos são essenciais ao pensar SI e facilmente associáveis com a prática de pesquisa, assim como habilitados pela autonomia de poder e capacidade do pesquisador. Por exemplo, enquanto o pesquisador nem sempre tem a capacidade financeira de publicar uma comunicação científica como acesso aberto, dependendo do preço, ele pode ter sua base de dados aberta online referenciando a mesma no próprio trabalho, por si.

Na Figura 6.4, complementada pela Tabela 6.4.2, é exposta uma taxonomia para transparência científica. Propósito responde por que a transparência está sendo habilitada; Audiência responde quem receberá os dados e informações transparecidos; Conteúdo apresenta o que será transparecido. Apresentando Como, temos Prazo apresentando as diversas opções temporais envolvidas no processo científico; Ator são as partes possibilitadas a comunicar o conteúdo científico; Mecanismo identifica e esclarece informações que podem assumir uma ampla variedade de formas; Local são os diferentes ambientes quais a comunicação científica pode ser transmitida e compartilhada. Por fim, adaptamos uma das dimensões de [Elliott 2020], e o que era "perigo" representamos como Risco. Este último trata das configurações ou consequências das iniciativas de transparên- 


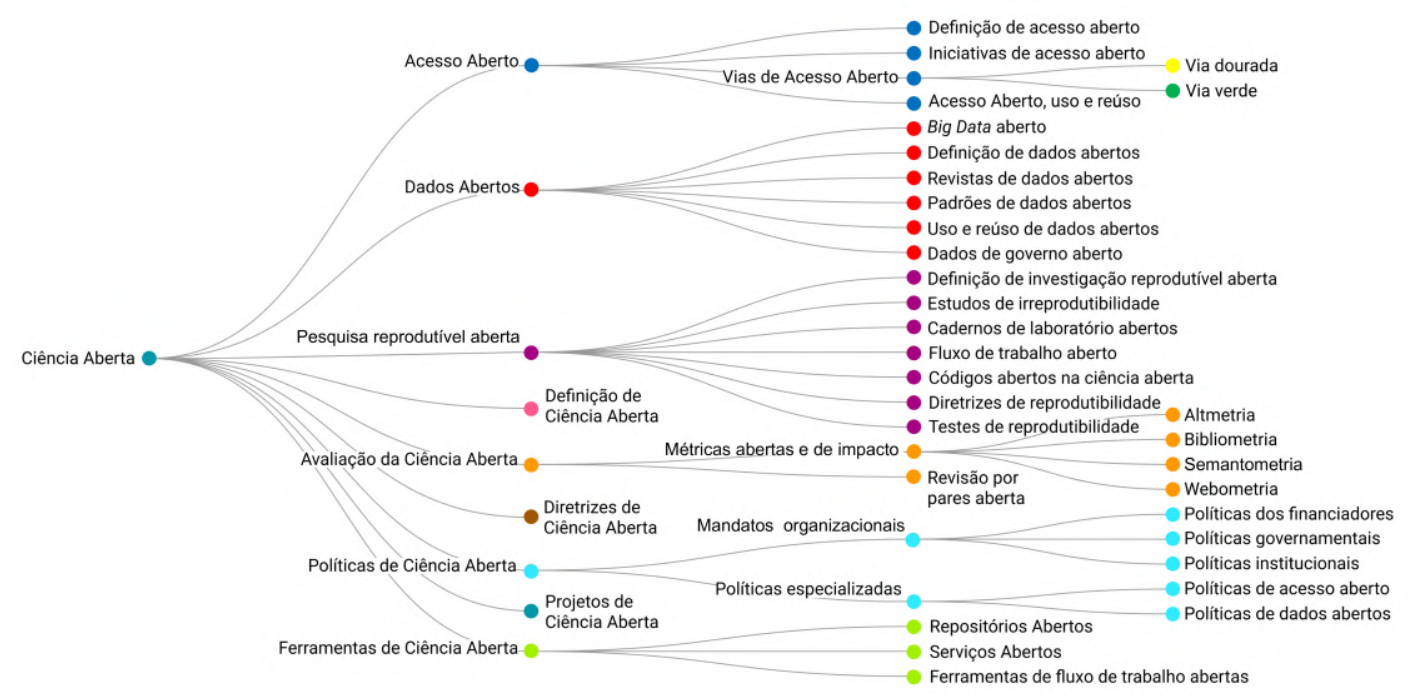

Figure 6.3. Taxonomia da Ciência Aberta [adaptado de [Pontika et al. 2015]]

cia que informam ou implementam as demais. Adaptamos para risco pois toda pesquisa científica apresenta riscos e perigo é (i) um termo "inflamado", nem sempre um perigo é interpretado como tal e inconscientemente a ideia de risco é inerente; (ii) presume má fé, rotular uma comunicação científica como "perigosa" estreita a abertura de ponderação para intensidade, i.e., uma pesquisa pode ser mais ou menos arriscada, enquanto para inaceitável ser mais ou menos "perigosa".

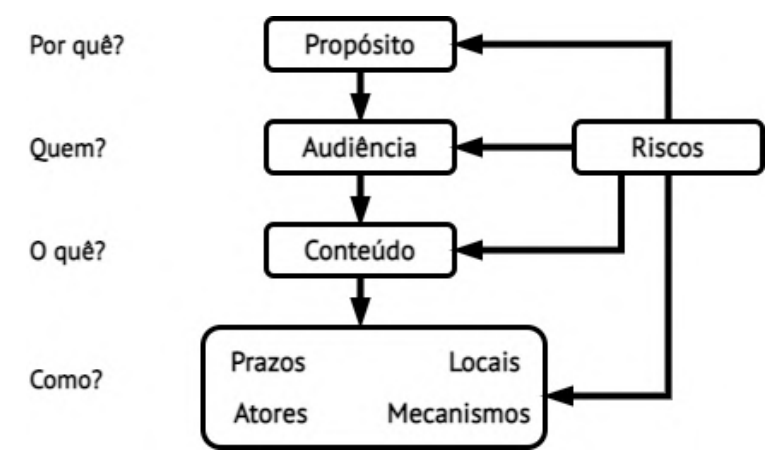

Figure 6.4. Representação de múltiplas dimensões nas quais as iniciativas de transparência podem variar, organizadas de acordo com quatro perguntas [adaptado de [Elliott 2020]]

Cada uma destas dimensões tem especificações extensas, detalhadas em [Elliott 2020]. Cada uma das dimensões e seus sub-itens podem ter desdobramentos próprios, como Audiência. Para comunicar-se com cada audiência específica há especificidades próprias, e uma forma de estabelecer este contato é utilizando Linguagens Cidadãs ou Claras, como para comunicar processos ao público-geral [Carvalho et al. 2020] ou problenas na comunicação gráfica de dados sobre COVID-19 [Oliveira et al. 2021].

Entretanto, a ideia de Ciência Aberta e Transparência deixa de ser trivial quando 
passa da ideia à práxis. A maioria dos autores, incluídos [Pontika et al. 2015] e [Elliott 2020], indicam definições, bases, conceitos e ideações sobre estes temas, entretanto a análise materialista é vazia ou quase nula. Isto é, o que deve ser feito; quais atores devem ser manobrados; quem tem a perder e a ganhar; os fenômenos negativos são restritos ou especiais à Ciência?; o ônus do problema é majoritariamente dos pesquisadores? Isto é, eles são relapsos, preguiçosos, apresentam interesses obscuros, dentre outros; o "fazer Ciência" mudou durante o Século XX ou se mantém ancorado na práxis do Século XVIII? E, principalmente, debater a moralidade acerca desta abertura de informações científicas.

É intuitivamente simples pleitear e defender a argumentação em favor da Ciência Aberta ou da Transparência Científica, principalmente quando a linha argumentativa envolve "progresso", "democracia" ou termos socialmente polêmicos e complexos de se contra-argumentar sem recair na falácia do Apelo ao Absurdo (Reduction ad absurdum), i.e., a Ciência "é Aberta" ou "é Fechada". Não há um meio termo ou o ônus da abertura científica recai majoritariamente sobre os pesquisadores individualizados, ou grupos de pesquisa/laboratórios isolados.

Vamos citar apenas um exemplo, o preço para se publicar uma pesquisa em uma comunicação científica considerada de alta qualidade no Brasil. No Brasil os pesquisadores são pontuados e categorizados, de quantificação à qualificação, através do sistema de avaliação QUALIS ${ }^{42}$. O capital moral e social do(s) pesquisador(es) é relacionado à sua produção e publicação de pesquisas nas melhores posições do QUALIS. O custo para publicar nos repositórios melhores qualificados pelo QUALIS variam entre US\$2000 e US $\$ 3000{ }^{43}$. Considerada a situação atual da cotação do dólar, flutuando em aproximadamente R\$5,00, uma publicação pode custar entre RS\$10000 e RS\$15000, em média. Um pesquisador arca com a maior parte das despesas, investimentos ou gastos, da sua produção científica, e além deste valor isolado há o gasto com viagem, estadia, inscrição em conferência, alimentação, transporte, isso considerando apenas o escopo acadêmicocientífico. Excluindo conferências? Sem problemas, temos os custos da edição, publicação, publicidade e divulgação científica de seu livro ou outra obra qualquer.

E considerando que as conferências e periódicos de melhor colocação no QUALIS são internacionais. E que os preços são em dólar. E que o dólar está, atualmente, cotado na flutuação próxima de $\mathrm{R} \$ 5,00$. Isso sem considerar custos secundários da prática acadêmica, que são ainda mais opacos ao sistema, como "jantar da conferência", transportes com certa qualidade para movimentação com equipamentos caros, colaboração financeira entre colegas, contratação de revisores para ajustes linguísticos, e reservas para quaisquer riscos. Transparência Científica é igualmente uma ameaça de tiro no pé e objeto de manobra para disputa ideológica econômico-política, por exemplo, por que pagar por "jantar da conferência"? Se é funcionário público, que use transporte público? Ao invés de se hospedar em hotel, que tal se hospedar em um hostel? Ao invés de viajar de avião, por que não suportar mais de 24 horas de viagem intermunicipal de ônibus?

Em suma, é óbvio que quando o debate recai em uma simplificação minimalista, será simples apontar "certo" e "errado" e similares. Entretanto podemos contra-

\footnotetext{
${ }^{42}$ https://pt.wikipedia.org/wiki/Qualis

${ }^{43}$ https://www.openaccess.cam.ac.uk/publishing-open-access/how-much-do-publishers-charge-openaccess. Disponível em: 01/09/2021
} 
Table 6.1. Oito dimensões da transparência científica [adaptado de [Elliott 2020]]

\begin{tabular}{|l|l|}
\hline \multicolumn{1}{|c|}{ Propósito } & \multicolumn{1}{c|}{ Audiência } \\
\hline Facilitar a reanálise de resultados & Cientistas envolvidos na pesquisa \\
\hline Melhorar a replicabilidade & Outros cientistas \\
\hline Promoção da inovação & Outros acadêmicos \\
\hline Manter a responsabilidade dos especialistas & Desenvolvedores de políticas \\
\hline Facilitar a interação crítica & Políticos e entidades políticas \\
\hline Promover a formulação de políticas de alta qualidade & Jornalistas \\
\hline $\begin{array}{l}\text { Capacitar o público a tomar decisões de acordo com } \\
\text { seus valores }\end{array}$ & Grupos de partes interessadas específicas \\
\hline Promover confiabilidade & Público geral \\
\hline \multicolumn{2}{|c|}{} \\
\hline Dados, métodos, código, materiais & Antes do início da pesquisa \\
\hline $\begin{array}{l}\text { Interpretações dos dados, métodos e código para } \\
\text { não especialistas }\end{array}$ & Ao longo do processo de pesquisa \\
\hline Julgamentos de valor de vários tipos & Imediatamente após os dados serem coletados \\
\cline { 1 - 2 } Valores ou fatores que influenciam os julgamentos & Após a publicação \\
\cline { 1 - 2 } Relatórios de deliberações subjacentes & $\begin{array}{l}\text { Durante ou após revisões ou análises subsequentes } \\
\text { da pesquisa }\end{array}$ \\
\hline Implicações de julgamentos de valor & \multicolumn{1}{|c|}{} \\
\hline
\end{tabular}

\begin{tabular}{|l|l|}
\hline \multicolumn{1}{|c|}{ Ator } & \multicolumn{1}{c|}{ Mecanismo } \\
\hline Cientistas que realizaram a pesquisa & Discussões entre cientistas (oral ou escrita) \\
\hline Outros cientistas & Colaborações interdisciplinares \\
\hline Acadêmicos trabalhando em outras áreas & Colaborações com membros da comunidade \\
\hline Jornalistas & Órgãos consultivos do governo e outras iniciativas \\
\hline Sociedades científicas & Processos contraditórios \\
\hline Agências governamentais & \\
\cline { 1 - 2 } $\begin{array}{l}\text { Organizações não governamentais e organizações } \\
\text { da sociedade civil }\end{array}$ & \multicolumn{1}{|l}{} \\
\cline { 1 - 2 } &
\end{tabular}

\begin{tabular}{|l|l|}
\hline \multicolumn{1}{|c|}{ Local } & \multicolumn{1}{c|}{ Risco } \\
\hline $\begin{array}{l}\text { Comunicação por cientistas (oral ou escrita, } \\
\text { incluindo mídia social) }\end{array}$ & Desperdiçar recursos escassos \\
\hline Registros e repositórios & Desacelerando a ciência \\
\hline Jornalismo científico & Prejudicar empresas \\
\hline Relatórios de agências governamentais & Violar privacidade \\
\hline $\begin{array}{l}\text { Relatórios de organizações não governamentais } \\
\text { ou grupos comunitários }\end{array}$ & Gerando ceticismo impróprio \\
\hline & Criar uma falsa sensação de confiança \\
\cline { 2 - 2 } & Causando confusão \\
\cline { 2 - 2 } & Facilitar esforços para assediar ou enganar \\
\\
\end{tabular}

argumentar tanto deontológica quanto teleologicamente, nenhum destes dois tópicos aqui presentes são tão simples quanto parecem.

\subsubsection{Consentimento, Assentimento e Comitê de Ética}

De modo a resguardar a integridade dos participantes de pesquisas científicas, a Comissão Nacional de Ética em Pesquisa (CONEP), vinculada ao Ministério da Saúde, determina várias Normas que devem ser seguidas pelas pesquisas que envolvem seres humanos. A CONEP é responsável por elaborar e atualizar as diretrizes e normas para a proteção dos sujeitos da pesquisa; avaliar e acompanhar os protocolos de pesquisa em áreas temáticas especiais e coordenar a rede de Comitês de Ética em Pesquisa das instituições [Cosac 2017]. Cada instituição pode ter um ou mais Comitês de Ética em Pesquisa (CEP), que é um colegiado interdisciplinar e independente, que delibera sobre a aprovação de projetos de pesquisa e tem como meta defender os interesses dos participantes de pesquisas, considerando sua integridade e dignidade.

Os Comitês de Ética em Pesquisa têm a sua origem justificada pelas atrocidades 
cometidas nas guerras do século passado. Logo, a princípio, as normas e diretrizes eram focadas em pesquisas da área biomédica. O Conselho Nacional de Saúde (CNS) lançou uma primeira Resolução em 1988. Ao longo desses primeiros anos o processo de submissão e avaliação de projetos foram se aprimorando e surgiram necessidades não supridas por essa resolução. Então, em 1996 foi lançada uma nova resolução denominada Resolução CNS no. 196/1996, que propunha como diferencial em relação à anterior quatro referenciais básicos da bioética: autonomia, não maleficência, beneficência e justiça, assegurando direitos e deveres dos pesquisadores e dos participantes das pesquisas, considerando fortemente aspectos ligados a pesquisas da área biomédica. E em 2012, essa resolução foi aperfeiçoada, tendo sido lançada a Resolução CNS no. 466/2012 [Brasil 2012].

Mas, com o passar do tempo e com a difusão de pesquisas em muitas áreas humanas e sociais, a atuação dos CEPs foram se ampliando e grupos dessas áreas iniciaram uma grande discussão nacional, que culminou na proposta de uma nova norma, que abarca pesquisas em áreas além da biomédica, a Resolução CNS no. 510/2016 [Brasil 2016b]. A Resolução 510/2016 tem como característica diferencial em relação à Resolução 466/2012 a não intervenção direta no corpo humano. Outro aspecto a destacar é a possibilidade de obter o consentimento para participação nas pesquisas de forma oral, ou por imagem.

E as pesquisas da área de SI, em que resolução se encaixam? A princípio pesquisas de testes de software, avaliações de usabilidade e da qualidade de interface, e testes de produtos de software para contextos educacionais se conectam mais fortemente com a Resolução 510/2016. Entretanto, se a pesquisa tiver participação de menores de 18 anos ou de pessoas com deficiência cognitiva, alguns aspectos específicos devem ser considerados. Neste caso, será necessária a autorização de um responsável.

Em março de 2018 foi publicada a Resolução CNS no. 580/2018 que trata de pesquisas que usam o Sistema Único de Saúde (SUS) [Brasil 2018b]. Em 2021, motivado pela pandemia de COVID-19, a CONEP publicou um Ofício ${ }^{44}$ para orientar pesquisadores e CEPs em relação a procedimentos que envolvam o contato com participantes e/ou coleta de dados em ambiente virtual.

A submissão de projetos ao CEP requer o preparo de vários documentos, para que os riscos éticos possam ser avaliados. A submissão é realizada na Plataforma Brasil 45 e vários documentos devem ser preparados considerando as resoluções vigentes. Para a realização do cadastro na plataforma é preciso ter a cópia de documento de identificação escaneado e o link do currículo LATTES.

O projeto deve ter informações que permitam avaliar possíveis riscos aos participantes e documentos anexos, que contemplam vários aspectos das resoluções associadas. De modo a ajudar na submissão do projeto na plataforma, alguns aspectos devem ser descritos no projeto: Resumo e Desenho da Pesquisa; Contextualização e objetivos; Definição da população e como será contatada; Método de coleta de dados; Riscos e benefícios; Orçamento; Instrumento de coleta de dados e Cronograma. Ressaltamos que não

\footnotetext{
${ }^{44}$ http://conselho.saude.gov.br/images/Oficio_Circular_2_24fev2021.pdf. Disponível em: 01/09/2021

${ }^{45}$ https://plataformabrasil.saude.gov.br/login.jsf. Disponível em: 01/09/2021
} 
são avaliados projetos já iniciados, ou realizados.

De acordo com a Resolução 466/2012 [Brasil 2012], o assentimento livre e esclarecido é voltado para o registro da anuência do participante da pesquisa, sendo criança, adolescente ou legalmente incapaz, que devem ser esclarecidos sobre a natureza da pesquisa, seus objetivos, métodos, benefícios previstos, potenciais riscos, considerando seu nível de compreensão e idade. Esta anuência é dada em um documento separado do Termo de Consentimento Livre e Esclarecido (TCLE) dos responsáveis. Logo, os pais/responsáveis assinam o TCLE, consentindo a participação de menores de idade ou pessoas com deficiência.

Os documentos a serem anexados na submissão são: TCLE (se for consulta a banco de dados é possível anexar um documento pedindo a dispensa); Termo de Consentimento do responsável (quando o participante for menor de idade); Termo de Assentimento Livre e Esclarecido (TALE) (para menor de 12-17 anos). Para menores de 12 anos, somente o responsável precisa assinar, mas não há impedimento das crianças também assinarem um documento de assentimento. Termo de Anuência da Instituição onde a pesquisa será realizada (TAI) com assinatura do responsável pelo setor onde a pesquisa se desenvolverá; Folha de rosto, devidamente preenchida e assinada pela direção, ou coordenação do local de vinculação do pesquisador principal. Em geral, para evitar conflitos de interesse: se o coordenador ou o diretor forem da equipe do projeto, eles não podem assinar a Folha de Rosto. Da mesma forma, o Termo de Anuência Institucional não pode ser assinado por pesquisador membro da equipe do projeto.

O TCLE deve ser escrito em forma de convite, com linguagem acessível ao seu público-alvo. Deve conter o objetivo; como será realizada a pesquisa; a possibilidade de desistência a qualquer momento, sem que cause prejuízo para o participante; os riscos e os benefícios; a não-remuneração; garantia do sigilo dos resultados; como serão publicados os resultados; a garantia do sigilo; o contato dos pesquisadores, o contato do CEP e os espaços para as assinaturas. Toda a pesquisa oferece riscos mínimos e isso deve estar explicito no projeto e no TCLE. Neste caso, pode ser um constrangimento, ou uma recuperação de memórias desagradáveis, manchas no braço por coleta de sangue, dentre outros. O TCLE deve conter claramente os procedimentos para minimizar os riscos. As filmagens devem ser explicitamente citadas no TCLE. E se forem realizadas para coleta de dados e transcrição, o texto explicativo deve estar no corpo do TCLE. Filmagens para exibição pública devem constar em parágrafo separado. Em geral, as instituições têm modelos da documentação em seus sites.

\subsection{Sobre os extremos e seus valores}

Do parcial ao imparcial, do neutro ao tendencioso, do enviesado ao sem viés, do isento ao comprometido, do ruidoso ao sem ruído, daquele com valor ao sem valor, do autônomo ao dependente... e as muitas mais variações deste binarismo irreal. Como autor central deste debate, recorremos à [Simon 2019] para dialogar com as Ciências do Artificial. Tecnologias alteram a realidade e a nossa realidade altera as tecnologias. Nós fazemos parte da realidade, tecnologias nos alteram e nós alteramos tecnologias. Todos somos dotados de valores morais, nossos valores morais alteram a realidade e a realidade altera nossos valores morais. Isto é, nossos valores morais alteram tecnologias e tecnologias 
alteram nossos valores morais. Esta relação dialógica ou dialética persiste há milênios, desde a ideação de tecnologias imateriais, como artefatos de comunicação.

O Painel Intergovernamental sobre Mudanças Climáticas (IPCC - Intergovernmental Panel on Climate Change) publicou um relatório em agosto de 2021 apontando que a humanidade está sendo conduzida à extinção através das mudanças climáticas, caso haja omissão de ações práticas para significativamente mitigá-la ou controlá-la. A responsabilidade principal é dos seres humanos ${ }^{46}$, enquanto diversos efeitos são inevitáveis e irreversíveis ${ }^{47}$. Dados e gráficos apontam que o arrefecimento deste fenômeno piora exponencialmente a partir de meados do Século XIX, coincidindo com a Revolução Industrial e proliferação tecnológica de produções massivas. É inegável de que os avanços tecnológicos alteraram substancialmente a vida dos seres humanos, positivamente em diversos aspectos, entretanto em outros aspectos estamos sendo conduzidos ao nosso próprio holocausto. O Brasil, por exemplo, parece estar indo na contramão dos esforços para melhoria climática ${ }^{48}$.

Podemos falar de plágio, normas jurídicas ou técnicas, comitês de éticas, ciência aberta e ainda outros muitos pontos associados à SI, entretanto, precisamos refletir na nossa responsabilidade para com a sustentabilidade da nossa região, do nosso país e do nosso planeta. Seria hipocrisia da nossa parte ignorar o macro-estrutural, porque foi justamente esta negligência macro-estrutural que contribuiu para uma pandemia de COVID-19.

Em um exemplo que une Ciência Aberta, divulgação científica, para instrução climática, o episódio "Poeira" (E03) ${ }^{49}$, da série "A Era dos Dados" (T01), expõe a relação entre a poeira que sai do deserto do Saara e chega à Amazônia, 27 bilhões de toneladas por ano. A poeira que sai do Chade, na África, tem função nutritiva para a vegetação na Bacia Amazônica. Milhares de toneladas de Fósforo são carregadas pelos ventos e ajudam no balanceamento ecossistêmico da floresta, a poeira traz elementos que reabastecem o que a chuva leva. Entretanto, isto não é tecnologia, não "é ético" e nem passível de moralidade, os ventos não escolhem interagir positivamente com a Bacia Amazônica, o deserto não escolheu ceder sua poeira e a Bacia Amazônica não demandou por estes recursos diretamente de uma região africana separada por um imenso oceano. Por outro lado, o desmatamento humano desenfreado está conduzindo a Floresta Amazônica ao ponto de "não retorno" ${ }^{50}$, nem a floresta, nem os ventos e nem o deserto africano tem participação moral ou ética neste cenário, apenas alguns seres humanos inescrupulosos e enviesados em favor desta prática. Desmatar a Amazônia é uma escolha ética, e apesar dos pareceres alarmantes seguidos, os atores que o fazem, e reforçam esta prática, seja simbólica ou concretamente, escolheram manter este curso de ação.

Você não estaria lendo este texto se não fosse pela Computação; cientistas não

\footnotetext{
${ }^{46}$ https://www.theguardian.com/environment/2021/aug/09/climate-crisis-unequivocally-caused-byhuman-activities-says-ipcc-report. Disponível em: 09/01/2021

${ }^{47}$ https://www.theguardian.com/science/2021/aug/09/humans-have-caused-unprecedented-andirreversible-change-to-climate-scientists-warn. Disponível em: 09/01/2021

${ }^{48} \mathrm{https}$ //www1.folha.uol.com.br/colunas/helio-mattar/2021/08/relatorio-mostra-que-o-brasil-caminhana-contramao-do-mundo.shtml. Disponível em: 01/09/2021

${ }^{49}$ https://www.imdb.com/title/tt12816820/?ref_=ttep_ep3. Disponível em: 01/09/2021

${ }^{50}$ https://www.bbc.com/portuguese/brasil-5046861. Disponível em 01/09/2021
} 
teriam estudado o fluxo da poeira de forma precisa se não fosse pela Computação; a divulgação científica agenciada pela Netflix não seria possível sem a Computação; a análise de que estamos chegamos ao ponto de "não retorno" florestal não seria tão acurado sem a Computação; as análises científica do IPCC não seriam possíveis sem a Computação. Por outro lado, toda a aceleração da destruição amazônica, escolha de localizações estratégicas para extração e comunicação das redes de desmatamento também não seria possível sem a Computação. Todos estes elementos são sistemas de informação.

Esclarecemos que esta instância serve como ilustração apenas e nossa intenção se afasta de uma agenda de urgência para que toda comunidade de Computação foque nas mudanças climáticas. O objetivo é mostrar do local ao macro-estrutural, do natural ao artificial, da complexidade e heterogeneidade dos valores e, por fim, da conscientização do poder prático que a Computação tem, seja no pensar ou no fazer. E quem determina a maioria das nossas próprias diretrizes éticas somos nós mesmos, através das tecnologias que nos cercam, e dos valores morais que são influenciados por elas e as influenciam.

Interagimos com a realidade baseados nas limitações das nossas subjetividades, nossas vivências, experiências, ideologias, identidades, limites cognitivos, conhecimentos, dentre outros. Assim como a realidade incide sobre nossas subjetividades. Simultaneamente, conforme aumentamos o grau de complexidade analítica da realidade, se torna menos categórica a valoração moral, ao ponto que deixamos de analisar "o que?" e partimos outros questionamentos como "para quem?", “como?", “quando?”, "por que?". Por exemplo, [Bender et al. 2021] levanta o questionamento do impacto sustentável que IAs colossais com milhões de linhas de código, como BERT, causam e as possíveis consequências negativas; como sustentabilidade natural e social. Uma das autoras de [Bender et al. 2021], Timnit Gebru, foi abruptamente desligada da empresa Google e uma explicação possível trata do seu envolvimento neste artigo crítico "atacando" IAs colossais, categoria na qual BERT se enquadra ${ }^{51}$. BERT faz parte do motor das pesquisas do Google, e foi parte determinante do lucro de US\$26 bilhões de dólares da empresa no terceiro quartil do ano. Isto é, os benefícios de IAs colossais suplantam seus possíveis revezes? Ou as mesmas são apenas ferramentas de lucratividades desenfreada? Com o cenário de mudanças climáticas atual, mesmo assim vale a pena? Por exemplo, qual impacto que BERT tem nas mudanças climáticas?

Cabe a nós, enquanto indivíduos ou coletividade organizada, reconhecer que a imparcialidade é um mito e que, apesar de almejarmos buscá-la, a parcialidade faz parte do ser humano, assim como das tecnologias e artefatos que desenvolvemos. Concretamente, inexiste algo totalmente bom ou mau, certo ou errado, justo ou injusto, e cabe a nós calibrar as análises a partir de ponderação ética consciente e racional. A totalidade cobre elementos diversos externos ao objeto em si, como público-alvo e possíveis consequências. Precisamos pensar nas responsabilidades e valores das nossas ações, seja do pensar ou do fazer [Lacey 2019] e das tecnologias e artefatos que idealizamos explicitamente, projetamos e implantamos [Shilton 2018].

\footnotetext{
${ }^{51}$ https://www.theverge.com/2020/12/5/22155985/paper-timnit-gebru-fired-google-large-languagemodels-search-ai. Disponível em: 01/09/2021
} 


\subsubsection{A história que se repete...}

[Silva 2020] categoriza o infame caso onde "Google Photos marca fotos de jovens negros com a tag 'Gorila", como uma microagressão de negação de cidadania e microinsulto. Este caso ocorreu em 2015. Em Setembro de 2021, o algoritmo do Facebook novamente associa pessoas pretas à "primatas" ${ }^{52}$, como ilustrado na Figura 6.5, o vídeo expõe uma pessoa preta e a plataforma questiona "Continuar vendo vídeos sobre Primatas?".

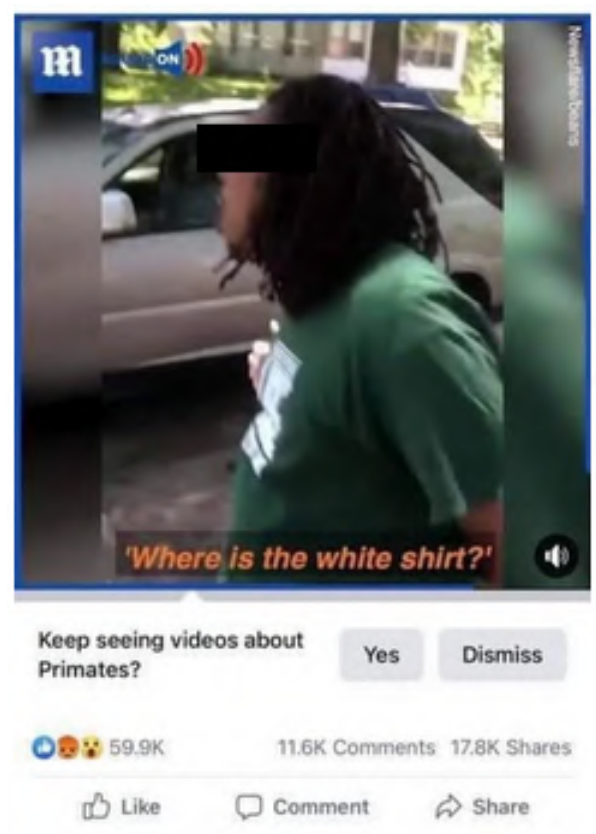

Figure 6.5. Caso explícito de racismo na plataforma Facebook

Rapidamente um porta-voz da empresa surgiu para pedir desculpas, e reiterar os esforços da organização para "prevenir que casos assim ocorram novamente" e que este é um "erro inaceitável". Darci Groves, uma ex-funcionária que foi gestora de conteúdo na empresa, "sugeriu que lidar com problemas de raça não é uma prioridade para os líderes [na empresa Facebook]" 53.

Analisando reações na própria plataforma Facebook, comentários são diversos, muitos com um posicionamento "defensivo" favorável à empresa ou à IA. Por exemplo, que nós todos realmente somos primatas; que a IA "aprendeu" com as interações de dados entre os usuários; que a IA é "lógica" e imparcial; que racistas são os usuários, não a IA; e acusações aleatórias entre usuários que não sabem o que é ou como funciona uma IA. [Benjamin 2019] apresenta um viés crítico sobre este tema, indo contra esta linha argumentativa de que todo o agenciamento do fenômeno racista tem o seu ônus na ação dos usuários, i.e., ele é um fato social em conformidade; e que o controlador intermediário é apenas um "facilitador" sem responsabilidade efetiva. Incluindo respaldos em sustentabilidade, como sustentabilidade social neste caso.

\footnotetext{
${ }^{52}$ https://www.nytimes.com/2021/09/03/technology/facebook-ai-race-primates.html. Disponível em 01/09/2021

${ }^{53}$ https://www.nytimes.com/2021/09/03/technology/facebook-ai-race-primates.html. Disponível em: $03 / 09 / 2021$
} 
Um dilema ético que necessita de superação nas RSO trata da responsabilização entre usuários, incluídos coletivos e organizações; a plataforma, o sistema em si; e as partes responsáveis, gestoras do sistema.

Após um dos casos mais escandalosos e imorais relacionados com desinformação e SI, a história se repete mais uma vez com uma nova roupagem, mas na mesma plataforma, com o mesmo corpo de líderes e fenômenos significativamente similares. O escândalo Cambridge Analytica, relacionado diretamente às eleições presidenciais nos EUA de 2016, foi um marco exemplar para Ética Computacional [Spinello 2020]. Novamente, agora nas eleições presidenciais de 2020, desinformações inundaram o Facebook e receberam seis vezes mais cliques se comparadas com informações factuais ${ }^{54}$, e mesmo que este fenômenos apresenta maior intensidade quando relacionado a usuários categorizados como de Direta, ocorre também com aqueles de Esquerda. Em resposta, a empresa Facebook respondeu que este quantitativo reflete apenas cliques, não quantas pessoas realmente viram o conteúdo. A quantidade de pessoas que, efetivamente, veem o conteúdo não é transparecida pela empresa.

Baseando-se em brechas interpretativas de seus próprios termos de uso, Facebook impede pesquisadores de realizar pesquisas com maior detalhamento e profundidade sobre os fenômenos de desinformação em sua plataforma ${ }^{55}$, bloqueia contas, cerceia acesso a dados, e apela a brechas contratuais. Ao serem impedidos de pesquisar, os pesquisadores alegam que a empresa busca formas de pará-los de analisar os fenômenos recorrentes em sua principal plataforma.

Concluindo, casos persistem e fenômenos se repetem. Pouco é efetivamente feito. Reforçamos que o pensar e o fazer devem seguir de mãos dadas, e como percebemos nestes breves exemplos, quem está fazendo está ignorando o que está sendo pensado, e quem está pensando está ingenuamente acreditando que o fazer irá simplesmente ou prontamente se adequar.

\subsection{Conclusão?}

Nesta obra cobrimos diversos pontos atravessados entre Ética, Computação, SI e Pesquisa. Todavia, eles foram um pingo no oceano de conteúdo que este tema oferece, e que abre lacunas, espaços, vias e um universo de possibilidades para análises profundas, ricas e que necessitam de qualidade ímpar. E esta qualidade não se esgota na Computação, porque a Computação é uma extensão da prática humana em um nível de refinamento e complexidade pouco intuitivo, e até um pouco perverso. Qual o nosso problema neste ponto? Construir um corpus de conhecimento para reflexão ética que habilite uma conscientização ética panorâmica, holística e epistemontológica [Escobar 2018] nos contextos, meios e cenários brasileiros. Dito isto, este trabalho não se conclui, e se lhe fizemos refletir, agora a "batata-quente" está com você. Nenhuma obra da Ética se conclui, porque a própria ideia de "concluir" um chamado à Ética é, por si só, absurdo à própria Ética.

Sobre o fazer SI, analisamos o quão pervasivo o WhatsApp está se tornando na

\footnotetext{
${ }^{54}$ https://www.washingtonpost.com/technology/2021/09/03/facebook-misinformation-nyu-study/. Disponível em: 03/09/2021

${ }^{55}$ https://www.nytimes.com/2021/08/10/opinion/facebook-misinformation.html. Disponível em: 01/09/2021
} 
realidade brasileira dos negócios; criticamos o estado discursivo de que uma Ética para SI está pautada em organizações privadas ou empresas, colocando organizações públicas e organizações semi-formais em segundo plano (ou em plano nenhum, descartando-as); trouxemos alguns exemplos de Códigos de Ética ou de Conduta, mostrando que os acordos morais variam entre coletividades; debatemos sobre normas jurídicas e técnicas, e pela própria previsão de [Moor 1985] a tendência é que nestes próximos anos a formulação de leis relacionadas à Computação, ou seu uso e aplicação, cresça, e que nem sempre estas leis considerarão o estado da moralidade ou apresentarão deliberação ética racional coerente; com a Computação "invadindo" todos os possíveis espaços, diversas variáveis entram na equação da tomada de decisão ética ao se tratar dos valores e das consequências associados às soluções computacionais.

Trouxemos a importância do atravessamento entre Ética e pesquisa em SI sobre o pensar SI, acima disso, do respeito e consideração à interdisciplinaridade da área. Plágio não se resume à texto, imagens ou tabelas, se estende para códigos de software e bases de dados; a Ciência Aberta e Transparência Científica são "objetivos" para uma democratização e abertura de diálogo ampla tanto entre estudiosos, cientistas ou o público externo à Academia, todavia tem seus percalços, como preços e disputas econômico-políticas, que apesar de saudáveis em um ambiente democrático podem ser enviesadas ao absurdo; e apontamos a importância de se respeitar os participantes das pesquisas, considerando sua identidade, solicitando assentimento às crianças e consentimento aos adultos, e envolvendo comitês de ética nas pesquisas computacionais com seres humanos participantes, alcançando uma validação institucional formal de que a respectiva prática científica teve deliberação ética ampla para ocorrer.

Por fim, estendemos o debate éticos aos extremos, à iminência do holocausto da raça humana, da complexidade sistêmica dos ecossistemas naturais e tecnológicos, apontando a importância, relevância e poder que a Computação oferece a todos nós, a comunidade e sociedade que nos cercam. Enquanto interessados no pensar-fazer computacional, principalmente de seus usos e aplicações pela área de SI, precisamos refletir com consciência ética sobre o nosso papel no todo, tanto das ações como inações, i.e., escolher não agir ou agir contra e combater.

Recorrendo a [Voltaire 2012]: a parcialidade não é uma condição agradável, mas a imparcialidade ou neutralidade são absurdas 56 .

\section{Referências}

[Anderson et al. 1993] Anderson, R. E., Johnson, D. G., Gotterbarn, D., e Perrolle, J. (1993). Using the new acm code of ethics in decision making. Commun. ACM, 36(2):98-107.

[Baase e Henry 2017] Baase, S. e Henry, T. M. (2017). Gift of Fire, A: Social, Legal, and Ethical Issues for Computing Technology. Pearson, New York, NY, $5^{\text {a }}$ edição.

[Bannister e Connolly 2011] Bannister, F. e Connolly, R. (2011). The trouble with transparency: A critical review of openness in e-government. Policy \& Internet, 3(1):1-30.

\footnotetext{
${ }^{56}$ Le doute n'est pas une état bien agréable, mais l'assurance est un état ridicule. A dúvida não é uma condição agradável, mas a certeza é absurda.
} 
[Barger 2008] Barger, R. (2008). Computer Ethics: A Case-Based Approach. Cambridge University Press, Cambridge, RU.

[Bender et al. 2021] Bender, E. M., Gebru, T., McMillan-Major, A., e Shmitchell, S. (2021). On the dangers of stochastic parrots: Can language models be too big? In Proceedings of the 2021 ACM Conference on Fairness, Accountability, and Transparency, FAccT '21, page 610-623, New York, NY, USA. Association for Computing Machinery.

[Benjamin 2019] Benjamin, R. (2019). Race After Technology: Abolitionist Tools for the New Jim Code. Polity Press, New York, NY.

[Bioni 2019] Bioni, B. (2019). Proteção de Dados Pessoais A função e os limites do consentimento. GEN, Barueri, Brasil.

[Bobbio 2019] Bobbio, N. (2019). Teoria do Ordenamento Jurídico. Edipro, $2^{a}$ edição.

[Bock et al. 2021] Bock, A., España, S., Gulden, J., Jahn, K., Nweke, L. O., e Richter, A. (2021). The ethics of information systems: The present state of the discussion and avenues for future work. Number 51 in ECIS 2021 Research-in-Progress Papers.

[Brasil 2012] Brasil (2012). RESOLUÇÃO No 466, DE 12 DE DEZEMBRO DE 2012. Disponível em 01/09/2021 em: https://cutt.ly/mmS8Eua.

[Brasil 2016a] Brasil (2016a). RESOLUÇÃO No 5, DE 16 DE NOVEMBRO DE 2016. Disponível em 01/09/2021 em: http://portal.mec.gov.br/docman/novembro2016-pdf/52101-rces005-16-pdf/file.

[Brasil 2016b] Brasil (2016b). RESOLUÇÃO No 510, DE 7 DE ABRIL DE 2016. Disponível em 01/09/2021 em: http://bit.ly/2fmnKeD.

[Brasil 2018a] Brasil (2018a). LEI N N 13.709, DE 14 DE AGOSTO DE 2018. Disponível em 01/09/2021 em: http://www.planalto.gov.br/ccivil_03/_ato20152018/2018/lei/L13709.htm.

[Brasil 2018b] Brasil (2018b). RESOLUÇÃO $\mathrm{N}^{\mathrm{o}}$ 580, DE 22 DE MARÇO DE 2018. Disponível em 01/09/2021 em: https://conselho.saude.gov.br/resolucoes/2018/Reso580.pdf.

[Bynum 2000] Bynum, T. W. (2000). The foundation of computer ethics. SIGCAS Comput. Soc., 30(2):6-13.

[Bynum 2018] Bynum, T. W. (2018). Computer and Information Ethics. In The Stanford Encyclopedia of Philosophy (Summer 2018 Edition). https://plato.stanford.edu/archives/sum2018/entries/ethics-computer/. Disponível em: 01/09/2021.

[Carvalho et al. 2020] Carvalho, L. P., Cappelli, C., e Santoro, F. M. (2020). BPMN Pra GERAL, Business Process Models in a Citizen Language. In XVI Brazilian Symposium on Information Systems, SBSI'20, New York, NY, USA. Association for Computing Machinery. 
[Carvalho et al. 2021a] Carvalho, L. P., Oliveira, J., e Santoro, F. M. (2021a). A PRESENÇA DE CONTEÚDOS SOBRE ÉTICA COMPUTACIONAL NA LITERACIA EM COMPUTAÇÃO INSTITUCIONAL BRASILEIRA. Encontro Virtual ABCiber 2021. (no prelo).

[Carvalho et al. 2021b] Carvalho, L. P., Oliveira, J., e Santoro, F. M. (2021b). COMPUTAÇÃO, LITERACIA E ÉTICA COMPUTACIONAL. UM ESTUDO EXPLORATÓRIO PELO CIBERESPAÇO BRASILEIRO. Encontro Virtual ABCiber 2021. (no prelo).

[Carvalho et al. 2021c] Carvalho, L. P., Suzano, J. A., Oliveira, J., e Santoro, F. (2021c). Ethics: What is the research scenario in the brazilian symposium sbsi? In Anais da VII Escola Regional de Sistemas de Informação do Rio de Janeiro, pp. 24-31, Porto Alegre, RS, Brasil. SBC.

[Cesário et al. 2020] Cesário, J., Flauzino, V., e Mejia, J. (2020). Metodologia científica: Principais tipos de pesquisas e suas caraterísticas. Revista Científica Multidisciplinar Núcleo do Conhecimento, 5(11):23-33.

[Cosac 2017] Cosac, D. C. d. S. (2017). Autonomia, consentimento e vulnerabilidade do participante de pesquisa clínica. Revista Bioética, 25:19-29.

[Darch 2004] Darch, C. (2004). Digital divide or unequal exchange? how the northern intellectual property rights regime threatens the south. International Journal of Legal Information, 32(2):488-501.

[de Pádua 2019] de Pádua, E. M. M. (2019). Metodologia da pesquisa: abordagem teórico-prática. Papirus Editora.

[Deigh 2010] Deigh, J. (2010). An Introduction to Ethics. Cambridge University Press, Nova Iorque.

[Dimoulis 2016] Dimoulis, D. (2016). Manual de Introdução ao Estudo do Direito. Revista dos Tribunais, $7^{\mathrm{a}}$ edição.

[Donia e Shaw 2021] Donia, J. e Shaw, J. (2021). Ethics and values in design: A structured review and theoretical critique. Science and Engineering Ethics, 27.

[Elliott 2020] Elliott, K. C. (2020). A Taxonomy of Transparency in Science. Canadian Journal of Philosophy, page 1-14.

[Escobar 2018] Escobar, A. (2018). Designs for the Pluriverse Radical Interdependence, Autonomy, and the Making of Worlds. Duke University Press, Durham, USA.

[Ferraz 2014] Ferraz, C. A. (2014). Ética Elementos Básicos. NEPFIL online, Pelotas, RS.

[Fieser 2020] Fieser, J. (2020). Ethics. In The Internet encyclopedia of philosophy. https://iep.utm.edu/ethics/. Disponível em: 01/09/2021. 
[Garbe 1909] Garbe, W. (1909). Índios Botocudos : foto 04. 1 fotografia. 17 x $12 \mathrm{~cm}$. Disponível em 01/09/2021 em: https://brasilianafotografica.bn.gov.br/brasiliana/handle/20.500.12156.1/570.

[Garon 2018] Garon, J. M. (2018). Reordering the chaos of the virtual arena: harmonizing law and framing collective bargaining for avatar actors and digital athletes. In Barfield, W. e Blitz, M. J., (eds), Research Handbook on the Law of Virtual and Augmented Reality, pp. 513-566. Edward Elgar Publishing, Cheltenham, Reino Unido.

[Gibson 2014] Gibson, K. (2014). An Introduction to Ethics. PEARSON, Nova Jérsey.

[Gyekye 2010] Gyekye, K. (2010). African Ethics. In The Stanford Encyclopedia of Philosophy (Fall 2011 Edition). https://plato.stanford.edu/archives/fall2011/entries/african-ethics/. Disponível em: 01/09/2021.

[Johnson 2008] Johnson, D. (2008). Computer Ethics. Pearson, $4^{\mathrm{a}}$ edição.

[Kohun et al. 2012] Kohun, F., Rodi, A. F., e Delorenzo, G. (2012). Does information systems suffer an identity crisis? a case study of confusion and misinformation. Issues in Information Systems, 13(2):328-335.

[Kon et al. 2020] Kon, F., Lago, N., Meirelles, P., e Denner, C. (2020). Direitos autorais, licenças e patentes. In Maciel, C. e Viterbo, J., (eds), Computação e sociedade: a profissão - volume 1, pp. 12-46. EdUFMT Digital, Mato Grosso, Brasil.

[Lacey 2006] Lacey, H. (2006). Relações entre fato e valor. Cadernos de Ciências Humanas - Especiaria, 6(16):251-266.

[Lacey 2019] Lacey, H. (2019). Adoção de medidas de precaução diante dos riscos no uso das inovações tecnocientíficas. Estudos Avançados, 33(95).

[Laudon e Laudon 2020] Laudon, K. e Laudon, J. (2020). Management Information Systems: Managing the Digital Firm. Pearson, New York, NY, $16^{\text {a }}$ edição.

[Marques 2016] Marques, I. C. (2016). História das ciências, estudos cts e os brasis. In Abertura do Scientiarum Historia.

[Marques 2014] Marques, R. M. (2014). ContribuiÇÕes À critica da propriedade intelectual. Tendências da Pesquisa Brasileira em Ciência da Informação, 7(2).

[Mascaro 2013] Mascaro, A. (2013). Estado e forma política. Boitempo.

[Masiero 2013] Masiero, P. C. (2013). Ética em Computação. EDUSP, São Paulo, SP.

[Mingers e Walsham 2010] Mingers, J. e Walsham, G. (2010). Toward ethical information systems: The contribution of discourse ethics. MISQ., 34(4):833-854.

[Moor 1985] Moor, J. H. (1985). What is computer ethics?*. Metaphilosophy, 16(4):266-275. 
[Moriarty 2021] Moriarty, J. (2021). Business Ethics. In The Stanford Encyclopedia of Philosophy (Summer 2021 Edition). https://plato.stanford.edu/archives/sum2021/entries/ethics-business/. Disponível em: 01/09/2021.

[Nunes e Pinheiro-Machado 2017] Nunes, M. A. S. N. e Pinheiro-Machado, R. (2017). Propriedade intelectual e busca de informação tecnológica na área da computação. In Araújo, R. M. e Chueri, L. O. V., (eds), Pesquisa e Inovação: Visões e Interseções, pp. 67-92. PUBL!T, São Paulo, SP.

[Oliveira et al. 2021] Oliveira, R., Cappelli, C., e Oliveira, J. (2021). An indicator of inefficient visualizations: The challenge of transparency during the covid-19 pandemic in brazil: An indicator of inefficient visualizations: The challenge of transparency during the covid-19 pandemic in brazil. In XVII Brazilian Symposium on Information Systems, SBSI 2021, New York, NY, USA. Association for Computing Machinery.

[Padilha et al. 2005] Padilha, M. I. C., Ramos, F. R. S., Borenstein, M. S., e Martins, C. R. (2005). A responsabilidade do pesquisador ou sobre o que dizemos acerca da ética em pesquisa. 14(1):96-105.

[Paradice et al. 2018] Paradice, D., Freeman, D., Hao, J., Lee, J., e (2018), D. H. (2018). A review of ethical issue considerations in the information systems research literature. Foundations and Trends $R$ in Information Systems: Vol. 2, 2(2):117-236.

[Pereira et al. 2015] Pereira, R., Baranauskas, M. C. C., e Liu, K. (2015). The value of values for hci: An informed discussion beyond philosophy. In Proceedings of the 14th Brazilian Symposium on Human Factors in Computing Systems, IHC '15, New York, NY, USA. Association for Computing Machinery.

[Perelman 2003] Perelman, M. (2003). Steal This Idea: Intellectual Property and the Corporate Confiscation of Creativity. Palgrave Macmillan.

[Pontika et al. 2015] Pontika, N., Knoth, P., Cancellieri, M., e Pearce, S. (2015). Fostering open science to research using a taxonomy and an elearning portal. In iKnow: 15th International Conference on Knowledge Technologies and Data Driven Business.

[Ramalho 2013] Ramalho, R. A. S. (2013). Tecnologia e Sociedade responsabilidades e desafios na Era da Informação Digital. UFSCar, São Carlos, SP.

[Ribeiro et al. 2020] Ribeiro, K. S. F. M., Maciel, C., e S. Bim, M. A. (2020). Gênero e tecnologias. In Maciel, C. e Viterbo, J., (eds), Computação e sociedade: a profissão volume 1, pp. 104-140. EdUFMT Digital, Mato Grosso, Brasil.

[Shilton 2018] Shilton, K. (2018). Values and ethics in human-computer interaction. Foundations and Trends® in Human-Computer Interaction, 12(2):107-171.

[Silva 2020] Silva, T. (2020). Comunidades, algoritmos e ativismos digitais: Olhares afrodiaspóricos. LiteraRUA, São Paulo, SP.

[Simon 2019] Simon, H. (2019). The Sciences of the Artificial. MIT Press, $3^{\mathrm{a}}$ edição. 
[Spinello 2020] Spinello, R. A. (2020). Cyberethics: Morality and Law in Cyberspace: Morality and Law in Cyberspace. Jones \& Bartlett Publishers, Burlington, MA, $7^{\text {a }}$ edição.

[Stahl 2012] Stahl, B. C. (2012). Morality, ethics, and reflection: A categorization of normative is research. JAIS, 13(8):636-656.

[Stair e Reynolds 2018] Stair, R. M. e Reynolds, G. W. (2018). Principles of Information Systems. CENGAGE Learning, Boston, MA, $13^{\mathrm{a}}$ edição.

[Tavani 2002] Tavani, H. (2002). The uniqueness debate in computer ethics: What exactly is at issue, and why does it matter? Ethics and Information Technology, 4.

[Voltaire 2012] Voltaire, J. M. (2012). Oeuvres Completes de Voltaire, volume 12. Nabu Press.

[Đurić e Gasevic 2013] Đurić, Z. e Gasevic, D. (2013). A source code similarity system for plagiarism detection. The Computer Journal, 56:70-86. 